IZA DP No. 5820

Labor Supply Elasticities in Europe and the US

Olivier Bargain

Kristian Orsini

Andreas Peichl

June 2011 


\title{
Labor Supply Elasticities in Europe and the US
}

\author{
Olivier Bargain \\ University College Dublin and IZA \\ Kristian Orsini \\ University of Leuven \\ Andreas Peichl \\ IZA, University of Cologne and ISER
}
Discussion Paper No. 5820
June 2011

IZA
P.O. Box 7240
53072 Bonn
Germany

Phone: +49-228-3894-0

Fax: +49-228-3894-180

E-mail: iza@iza.org

\begin{abstract}
Any opinions expressed here are those of the author(s) and not those of IZA. Research published in this series may include views on policy, but the institute itself takes no institutional policy positions.

The Institute for the Study of Labor (IZA) in Bonn is a local and virtual international research center and a place of communication between science, politics and business. IZA is an independent nonprofit organization supported by Deutsche Post Foundation. The center is associated with the University of Bonn and offers a stimulating research environment through its international network, workshops and conferences, data service, project support, research visits and doctoral program. IZA engages in (i) original and internationally competitive research in all fields of labor economics, (ii) development of policy concepts, and (iii) dissemination of research results and concepts to the interested public.
\end{abstract}

IZA Discussion Papers often represent preliminary work and are circulated to encourage discussion. Citation of such a paper should account for its provisional character. A revised version may be available directly from the author. 


\section{ABSTRACT}

\section{Labor Supply Elasticities in Europe and the US*}

Despite numerous studies on labor supply, the size of elasticities is rarely comparable across countries. In this paper, we suggest the first large-scale international comparison of elasticities, while netting out possible differences due to methods, data selection and the period of investigation. We rely on comparable data for 17 European countries and the US, a common empirical approach and a complete simulation of tax-benefit policies affecting household budgets. We find that wage-elasticities are small and vary less across countries than previously thought, e.g., between .2 and .6 for married women. Results are robust to several modeling assumptions. We show that differences in tax-benefit systems or demographic compositions explain little of the cross-country variation, leaving room for other interpretations, notably in terms of heterogeneous work preferences. We derive important implications for research on optimal taxation.

JEL Classification: $\quad$ C25, C52, H31, J22

Keywords: $\quad$ household labor supply, elasticity, taxation, Europe, US

Corresponding author:

Olivier Bargain

UCD

Newman Building

Dublin 4

Ireland

E-mail: olivier.bargain@ucd.ie

\footnotetext{
* The authors are grateful to R. Blundell, M. Dolls, D. Hamermesh, D. Neumann, S. Siegloch, A. van Soest and participants to seminars/workshops at UCD, IZA, ISER, Leuven, ZEW. Research was partly conducted during Peichl's visit to the ECASS and ISER and supported by the Access to Research Infrastructures action (EU IHP Program) and the Deutsche Forschungsgemeinschaft (PE1675). We are indebted to the EUROMOD consortium and to Daniel Feenberg and the NBER for granting us access to TAXSIM and for help with the simulations. The ECHP was made available by Eurostat; the Austrian version by Statistik Austria; the PSBH by the Universities of Liège and Antwerp; the Estonian HBS by Statistics Estonia; the IDS by Statistics Finland; the EBF by INSEE; the GSOEP by DIW Berlin; the Greek HBS by the National Statistical Service; the Living in Ireland Survey by the ESRI; the SHIW by the Bank of Italy; the SEP by Statistics Netherlands; the Polish HBS by the University of Warsaw; the IDS by Statistics Sweden; and the FES by the UK ONS through the Data Archive. Material from the FES is Crown Copyright and is used by permission. The usual disclaimer applies.
} 


\section{Introduction}

The study of labor supply behavior continues to play an important role in policy analysis and economic research. In particular, the size of labor supply elasticities is a key component when evaluating tax-benefit policy reforms and their effect on tax revenue and employment. It may also crucially affect the conclusions of optimal tax applications (e.g., Saez, 2001), the specification of empirical real business cycle models (e.g., Kimmel and Kniesner, 1998, or Kydland, 1995) or the results of computable general equilibrium models (e.g., Bovenberg et al., 2000, or Ballard et al., 1985). Yet there is a great variation in the magnitude of elasticities found in the literature, and little agreement among economists on the size of elasticity that should be used in economic policy analyses (Fuchs et al., 1998). Differences across countries may be crucial on many accounts. For instance, whether an incentive policy like the US Earned Income Tax Credit (EITC) could work in continental Europe depends fundamentally on local labor supply behavior. More generally, differences across countries may play a key role when comparing the optimality of welfare regimes (see Immervoll et al., 2007) or when questioning the implications of an EU-wide tax system or the difference in mean work hours between Europe and the US (Prescott, 2004).

Several excellent surveys exist that report evidence on elasticities for different countries and different periods. Those written in the 1980s mainly focus on estimations using the continuous labor supply model of Hausman (1981) and provide evidence essentially for individuals in couples (Hausman, 1985, Pencavel, 1986, for married men, Killingsworth and Heckman, 1986, for married women). More recent surveys incorporate other methods and point to a relative consensus on some key findings (see Blundell and MaCurdy, 1999, and Meghir and Phillips, 2008). ${ }^{1} \quad$ Yet evidence is scattered and a lot of heterogeneity in estimated elasticities is observed. For instance, Blundell and MaCurdy (1999) report uncompensated wage elasticities ranging from -0.01 to 2.03 for married women. Admittedly, much of the variation in labor supply estimates across studies is due to different choices made by the analysts, including the type of data used (e.g., tax register data versus interview-based surveys), the data selection (e.g., focusing on households with or without children), the empirical approach (e.g., natural experiments; continuous or discrete structural models; models accounting or not for taxes, transfers and work costs, etc.,

\footnotetext{
${ }^{1}$ In brief, this consensus establishes that income elasticities are generally small and negative; own wage elasticities are usually large for married women, smaller and sometimes negative for men; wage elasticities are mostly driven by changes at the participation margin (Heckman, 1993). Note that elasticities found in the macroeconomic literature, often obtained by calibration of general equilibrium models (e.g., Prescott, 2004), are generally much larger than in microeconomic studies. Several reasons have been suggested, including different timing of adjustments (Chetty et al., 2009).
} 
see the discussions in Evers et al., 2008). The period of observation is also important, since elasticities within a country can change dramatically over time (see Heim, 2007, for the US). Beyond these differences in the way we measure elasticities, the question is whether genuine differences exist between countries, which could be explained by different demographic compositions, tax-benefit systems, labor market conditions and cultural backgrounds.

The present paper aims to shed some light on this question. We first review existing evidence for Europe and the US, then undertake the task of reassessing wage and income elasticities of labor supply in a comparable way for a large number of countries. In methodological terms, the ideal situation would be to use a generally agreed-upon standard estimation approach that also allows comparable measures across countries. Recent practice has focused on natural experiments, and notably changes in tax-benefit regulations, that can be used to assess labor supply responsiveness. Obviously, no reform can be found that would allow labor supply responses across countries to be compared. Even if, say, a European-wide tax reform existed, we could not tell whether different responses across EU states were due to different behavior or, for instance, to the interaction of the policy change with different tax-benefit systems. In this situation, the only way to compare countries consistently is to rely on a common structural model that allows predicting elasticities in a uniform fashion. We opt for a flexible discrete-choice model, as used in well-known contributions for Europe (van Soest, 1995, Blundell et al., 2000) or the US (Hoynes, 1996, Eissa and Hoynes, 2004). Importantly, this model can account for the comprehensive effect of tax-benefit policies on household budgets. First, this might allow explaining some of the international differences in labor supply elasticities. Second, and more importantly, nonlinearities and discontinuities from tax-benefit rules improve the identification of the model (together with demographic heterogeneity and some spatial and time variation in net wages). Our estimations are conducted on 25 representative micro-datasets covering 17 European countries and the US, with two years of data for some countries. Datasets cover a relatively narrow period, which facilitates cross-country comparison. We provide detailed estimates for different demographic and income groups, both at the intensive margin (worked hours) and extensive margin (participation).

The paper is easily positioned in the literature. To our knowledge, only Evers et al. (2008) gather evidence for a large set of countries, including several EU member states. While their meta-analysis controls for differences in countries, methods and other aspects, there may not be enough variations across studies - and not enough studies per country to isolate genuine international differences from other factors. More specific studies have also been suggested where a common labor supply estimation strategy is used to study the effect of a uniform reform in different European countries, e.g., a basic-income flat-tax 
reform for Italy, Norway and Sweden in Aaberge et al. (2000) or different income-tax principles for Denmark, Germany, Ireland and the UK in Smith et al. (2003). The special issue of the Journal of Human Resources published in 1990 has also provided evidence from different countries using the Hausman approach (see the introduction of Moffitt, 1990). We are not aware, however, of a systematic attempt to estimate and compare labor supply responsiveness over a large number of countries using a relatively harmonized approach that nets out possible differences due to data, periods and methods. In fact, such a comprehensive characterization was not possible in the past. Indeed, the present study benefits from a unique set of comparable data and from tax-benefit calculators now made available for numerous European countries (EUROMOD) and the US (TAXSIM). To this we add a considerable computational effort to estimate labor supply models for all countries and for various specifications. In particular, we check whether elasticities vary with the functional form (the flexibility of the utility function) and with the hour choice set (from a basic 4-choice model to a much narrower discretization bringing the model close to a continuous one). The complete analysis is based on nine different specifications, three demographic groups (couples, single women and men) and 25 different countries $\times$ periods, hence a total of 625 maximum likelihood (ML) estimations. We show that estimates are relatively stable across model specifications, giving confidence in the results and conveying that the size of elasticities is not driven by methodological choices.

Results are presented as follows. In Section 2, we review the existing methods and the available evidence regarding elasticities in Europe and the US. In Section 3, we describe the empirical approach while the main results are reported and discussed in Section 4. We show that cross-country differences in labor supply elasticities exist but are relatively small. When accounting for nonlinear taxation, fixed costs of work and joint labor supply in couples, we also find that wage elasticities of hour and participation are overall fairly modest. In particular, estimates for married women stand in a narrow range between .2 and .6, with significantly larger elasticities obtained for countries where female participation is lower (Greece, Spain, Ireland). Estimates for married men are closer to zero and show little variation. A larger variance is found for single women, with estimates between .1 and .6, which is due to the prevalence of single mothers in some countries. More variation exist when considering different income groups, with particularly large elasticities (sometimes larger than 1) among low-wage single individuals in some countries. This result, i.e., higher responsiveness in the low part of the income distribution, has crucial implication for welfare analysis (see Eissa et al., 2008). In Section 5, we focus on married women to analyze international differences. We investigate the role of tax-benefit systems, country-specific demographic composition (age, education and childbearing patterns) and selection into marriage as possible explanatory factors of international variation in the 
size of elasticities. These factors explain in fact very little, suggesting that cross-country variation may be due to heterogeneity in individual preferences towards work and, additionally, in social preferences which lead to contrasted childcare institutions. Interestingly, this result is similar to the time change in elasticities for the US (Heim, 2007 interprets the decline in elasticities over time as reflecting cross-cohort changes in preferences toward work). Section 6 concludes and derives implications for optimal taxation. Importantly, (i) the levels of elasticities, on average and across income groups, (ii) the correlation with participation rates and (iii) the gender differences in elasticities reported in the present study can significantly enrich the applications of the optimal tax literature along several dimensions, including the traditional equity-efficiency trade-off, the issue of whether financial support should be directed to workless poor or to working poor (Immervoll et al., 2007, Blundell et al., 2008) and the issue of joint versus individual taxation in couples (Immervoll et al., 2011).

\section{Methods and Existing Evidence}

The principal object of examination in this study is the size of wage and income elasticities, which are standard representations of labor supply responsiveness and particularly convenient when conducting international comparisons. To start with, we present a brief account of the available techniques to estimate labor supply, then discuss some of the evidence, reported for European couples in Tables 1 and 2, for European single individuals in Table 3 and for the US in Table $4 .^{2}$ This survey essentially distinguishes between estimates based on the Hausman approach, discrete-choice models and other methods. We put a certain emphasis on the studies based on discrete models with taxation, as this is the method we use and because of the skyrocketing number of such studies to analyze policies in the recent years. Yet we do not pretend to be exhaustive, simply to give a sense of the range of elasticities obtained in the literature for Europe and the US. ${ }^{3}$ Notice, however, that this survey substantially completes previous reviews, notably Blundell and MaCurdy (1999) and Meghir and Phillips (2008), who concentrate mainly on evidence from the Hausman model, for the 1980s and 1990s and for Anglo-Saxon countries.

Arguably, the Hausman approach was most often restricted to the case of piecewise linear and convex budget sets, hence a partial representation of the effect of tax-benefit policies on household budget constraints. MaCurdy et al. (1990) have also emphasized

\footnotetext{
${ }^{2}$ To keep our reference list reasonably short, Tables 1-3 refer, for most of the cited studies, to four surveys which gather all the exact references.

${ }^{3}$ Note also that we do not cover dynamic models or other margins than hour/participation (migration, tax evasion, work effort, etc.). Evidence on the elasticities of taxable income, as obtained from natural experiments, is surveyed in Meghir and Phillips (2008).
} 
that the combination of restrictive functional forms (linear labor supply) and estimation methods that impose theoretical consistency of the labor supply model everywhere in the sample (global satisfaction of Slutsky conditions) leads to biased estimates and possibly an overstatement of work incentives (see Heim and Meyer, 2003). In contrast, the discretechoice approach requires the explicit parameterization of consumption-leisure preferences as it assumes that labor supply decisions can be reduced to choosing among a discrete set of possibilities (e.g., inactivity, part-time and full-time). Thus, there is no need to restrict preferences and, in particular, to impose their convexity. In practice, specific utility functions are used, and we shall check whether the degree of flexibility makes a difference. The discrete approach also solves several other problems encountered with the Hausman method, which explains its relative success over the years. Firstly, discrete models directly account for both participation and working-time decisions (non-participation is just one of the discrete options). This is important, as most of labor supply adjustments occur along this margin (Heckman, 1993, Eissa and Hoynes, 1996). Secondly, consumption (disposable income) needs to be assessed only at certain points of the budget curve so that complex tax-benefit systems, that generate nonlinear budget constraints and nonconvex budget sets, can easily be dealt with. However, in order to maintain computational feasibility, the number of choices is typically limited to commonly agreed durations of work. We shall check whether moving closer to the continuous case affects the estimated elasticities (see also Heim, 2009, for a model combining continuous and discrete dimensions). A narrower discretization may also help to capture peaks which are not necessarily identical across countries (i.e., the overtime option in the US) in a cross-country analysis like ours. Thirdly, work costs, which also create nonconvexities, and joint decisions in couples are dealt with in a relatively straightforward way in the discrete approach. ${ }^{4}$

A crucial aspect is the identification of behavioral parameters. Estimates obtained with the Hausman approach are often contaminated by measurement errors (the division bias) and by assuming wage exogeneity. That is, unobserved characteristics (e.g., being a hard-working person) influence both wages and work preferences so that estimates obtained from cross-sectional wage variation across individuals are potentially biased. Arguably, natural experiments based on tax reforms do a better job as they directly

\footnotetext{
${ }^{4}$ Discrete models do not solve all the problems, however. One of the remaining issues is the fact that some of the choices may not be available to some people because of institutional constraints or individual/job characteristics. Due to a lack of information, and the large number of countries in our study, we do not deal with this constraint in an elaborated way - which may limit the comparability of our results - but simply account for it through specific parameters as explained below. Several studies suggest interesting ways to circumvent the problem, either by allowing the choice set to vary with individual characteristics (Aaberge et al., 1995) or by modeling the degree of captivity, possibly due to institutional constraints, to each observed hours alternative (Duncan and Harris, 2002). Several authors also use desired hours rather than observed hours (e.g., van Soest and Das, 2001).
} 
identify responses to exogenous variations in net wages, provided that control groups are well defined or that discontinuities in RD estimations are not due to other factors than the policy under study. The recent literature has exploited tax-benefit reforms of the 1980s and 1990s in the US, and to some extent in the UK, to assess labor supply responsiveness (e.g., US income tax reforms, AFDC/TANF reforms, extension of the EITC or the UK tax credit). Many of these important studies report the effects of reforms - see the survey of Holz and Scholz (2003) for the US - but not comparable elasticity measures, so they were not included in our survey (e.g., Bingley and Walker, 1997, Hoynes, 1996, Eissa and Liebman, 1996). Also, most of these reforms concerned families with children so that very few estimates are available for childless single individuals, as we can see in Table 4 for the US. Moreover, the lack of important reforms or policy discontinuity in Europe, or the under-use of them by European researcher, is reflected in Tables 13 where most studies are based on the estimation of structural models with taxation (a notable exception is the UK). A few studies use grouped data estimations of the correlation between hours/participation and wages over a long period to address the problem of measurement error in hourly wages (e.g., Devereux, 2004). Discrete models hold an intermediary position between natural experiments and the Hausman approach. Wage endogeneity problem may exist, yet these models account for nonlinear taxation in household budgets, which may create exogenous variation in net wages across regions, periods of time and demographic groups, and hence improve model identification. We discuss this point in detail in the next section.

From Tables 1 and 2, a first observation is that early evidence using the Hausman technique points to relatively large own-wage elasticities for married women, sometimes close to 1, or even larger, for instance in early studies for France, Germany, Italy or the UK. In contrast, recent evidence based on discrete-choice models shows more modest elasticities for this group, in a range between .1 and .5, with some exceptions. Several explanations provided in the literature pertain to the arguments made above, including the MaCurdy critique, the fact that fixed costs are ignored or simply that these elasticities were collected mainly in the $80 \mathrm{~s}$, when female participation was still relatively low in many countries. ${ }^{5}$ In Table 4 , we observe a similar pattern for the US, with very large estimates in early studies, including Hausman (1981), and more reasonable elasticities in the recent studies (hour elasticities ranging between .2 and .4). It should be noted that estimates are very similar whether they stem from reduced-form estimations (Devereux, 2004), natural experiments (Eissa and Hoynes, 2004) or structural models (Heim, 2009). As expected, estimates for married men are much smaller and often not significant or even

\footnotetext{
${ }^{5}$ More recent evidence coincides with rising participation rates and a mechanical decline in female elasticity, as established for the US in Blau and Kahn (2005) and Heim (2007).
} 
negative. There are few exceptions, with more substantial male elasticities in Ireland and for some of the German studies. Evidence for childless single individuals is very limited and point to very small elasticities. It is possible that participation responses might be more significant for low-skilled workers (see suggestive evidence in Eissa and Liebman, 1996, and the discussion in section 4). More numerous studies are available concerning single mothers. This group has received much attention because of higher risk of poverty and the fact that these women are usually more responsive to financial incentives. This is confirmed in Table 3, where relatively large elasticities are shown, especially for Sweden, the UK and the US.

It is noticeable that studies for a given country sometimes report very different magnitudes, even when the same method is used. For instance for the US, married women's wage elasticity obtained with the Hausman approach vary from .28 (Triest) to .97 (Hausman), depending on the constraints put on the model (see the discussion in Heim and Meyer, 2003). For France, estimates for married women are also very high with the basic Hausman model, but almost zero when introducing fixed costs (in this case, the model account only for variations in hours, cf., Bourguignon and Magnac, 1990). Estimates obtained with discrete-choice models are somewhat more comparable from one study to the next. Yet there are still differences, which are more likely driven by selection criteria (for France, high elasticities are found for families with children in Choné et al., 2003) and the type of data (administrative data in Laroque and Salanié, 2002, household surveys in Bargain and Orsini, 2006). Specifications and modeling choices may however play a role in the discrete approach as well, for instance regarding the treatment of couples (e.g., male-chauvinistic model in Bargain and Orsini, 2006, joint decisions in Bargain et al., 2009). It is rare to find several studies focusing on the same country and using a similar empirical approach, which would offer an interesting confidence interval (this exists for Germany, with fairly consistent results for married women, yet relatively contrasted estimates for single women across studies).

What can be learned from international comparisons at this stage? Focusing on married women, for whom we have the largest number of studies, we can observe that larger elasticities prevail in countries where women's participation is low. This is particularly true for Ireland (see Callan et al., 2009) and Italy (see Aaberge et al., 2002). In contrast, women's participation is high in Nordic countries and elasticities tend to be fairly small (an exception is Blomquist and Hansson-Brusewitz, 1990, for Sweden, but the authors examine data from the 1980s, while more recent evidence by Flood et al., 2004, confirm small hour elasticities for this country). Comparing Italy and Norway/Sweden, Aaberge et al. (2000) show that lower participation rates among married women in Southern Europe leads to a larger potential for reforms that increase financial incentives to work. Apart from these extreme cases, differences across countries may not be very large, as suggested 
by Evers et al. (2008). However, comparisons are muddled by all the methodological differences highlighted above and are incomplete (estimates are missing for several countries and demographic groups). The remainder of this study aims to fill some of this gap by estimating labor supply elasticities in a comparable fashion in 17 European countries and the US and for all demographic groups.

\section{A Common Empirical Approach}

\subsection{Model and Identification}

Model and Specification. We essentially follow van Soest (1995), Hoynes (1996) and Blundell et al. (2000) and refer to these studies for more technical details. In our baseline, we specify consumption-leisure preferences using a quadratic utility function, that is, the deterministic utility of a couple $i$ at each discrete choice $j=1, \ldots, J$ can be written as:

$$
\begin{aligned}
U_{i j}= & \alpha_{c i} C_{i j}+\alpha_{c c} C_{i j}^{2}+\alpha_{h_{f} i} H_{i j}^{f}+\alpha_{h_{m} i} H_{i j}^{m}+\alpha_{h_{f f}}\left(H_{i j}^{f}\right)^{2}+\alpha_{h_{m m}}\left(H_{i j}^{m}\right)^{2} \\
& +\alpha_{c h_{f}} C_{i j} H_{i j}^{f}+\alpha_{c h_{m}} C_{i j} H_{i j}^{m}+\alpha_{h_{m} h_{f}} H_{i j}^{f} H_{i j}^{m}-F_{i j}
\end{aligned}
$$

with household consumption $C_{i j}$ and spouses' worked hours $H_{i j}^{f}$ and $H_{i j}^{m}$. The $J$ choices of a couple correspond to all combinations of the spouses' discrete hours. Coefficients on consumption and work hours, namely $\alpha_{c i}, \alpha_{h_{f} i}$ and $\alpha_{h_{m} i}$, are household-specific and vary linearly with several taste-shifters (polynomial form of age, presence of children or dependent elders and region). The term $\alpha_{c i}$ also incorporates unobserved heterogeneity for the model to allow random taste variation and unrestricted substitution patterns between alternatives. The fit is improved by the introduction of fixed costs of work as in Callan et al. (2009) or Blundell et al. (2000). Fixed costs explain the fact that there are very few observations with a small positive number of worked hours. These costs, denoted $F_{i j}$ and non-zero for positive hour choices, also depend on observed characteristics and are expressed here in utility metric since they may correspond to actual costs (childcare) or psychological costs (leaving the children with strangers). They may also capture demandside constraints and the availability of jobs (see Aaberge et al., 1995). Note that fixed costs are only parametrically identified, i.e., a very flexible utility function could pick up the gap in the distribution at few hours (see van Soest et al., 2002). This militates in favor of relaxing usual regularity conditions on leisure/labor supply (see the methodological discussion in section 2 and Heim and Meyer, 2003). More generally, as we specify utility directly and not a labor supply function, tangency conditions are not required, and hence we simply check quasi-concavity of the utility function a posteriori. The only restriction to our model is the imposition of increasing monotonicity in consumption, which seems a minimum requirement for meaningful interpretation and policy analysis. Hence, the 
"structural" aspect of the model is not very constraining, and the restrictions due to the functional form can also be relaxed (in the next section, we check the robustness of our results to alternative specifications). For each labor supply choice $j$, disposable income (equivalent to consumption in the present static framework) is calculated as a function

$$
C_{i j}=d\left(w_{i}^{f} H_{i j}^{f}, w_{i}^{m} H_{i j}^{m}, y_{i}\right)
$$

of female earnings, male earnings and non-labor income $y_{i}$. The tax-benefit function $d$ is simulated using calculators that we present in the next section. Male and female wage rates $w_{i}^{f}$ and $w_{i}^{m}$ for each household $i$ are predicted using calculated wage rates from data information on workers and Heckman-corrected wage estimations. Because the model is nonlinear, the wage-rate prediction errors can be taken explicitly into account for a consistent estimation. The deterministic utility is completed by i.i.d. error terms $\epsilon_{i j}$ for each choice assumed to represent possible observational errors, optimization errors or transitory situations. Under the assumption that error terms follow an extreme value type I (EV-I) distribution, the (conditional) probability for each household of choosing a given alternative has an explicit analytical solution (a logistic function of deterministic utilities at all choices). The unconditional probability is obtained by integrating out the disturbance terms (unobserved heterogeneity and the wage error term) in the likelihood. In practice, this is done by averaging the conditional probability over a large number of draws, and the simulated likelihood function can be maximized to obtain all estimated parameters (Train, 2003). ${ }^{6}$ The model for single individuals (with or without children) is the same as above with only one hour term $(J$ is simply the number of discrete options for this person).

Identification. First of all, we predict wages for all observations, as explained above, in order to reduce some of the bias due to measurement errors on wages stemming from the division bias. In addition, accounting fully for tax-benefit policies helps to create some variation in net wage between people with the same gross wage. That is, individuals face different effective tax schedules, i.e., different actual marginal tax rates or benefit withdrawal rates, because of their different circumstances (different marital status, age, family compositions, home-ownership status, disability status) or different levels of nonlabor income. Using nonlinearities and discontinuities generated by the tax-benefit system in this

\footnotetext{
${ }^{6}$ We also insist on the fact that the two-stage approach used here is common practice (see Creedy and Kalb, 2005). Simultaneous estimations of wages and labor supply seem the ideal approach, yet this approach is rarely adopted (among exceptions, see Laroque and Salanié, 2001). The reason is that tax-benefit simulations must be run at each iteration of the ML estimation, which requires that they are available in the same computer language (this is not the case with EUROMOD) and which also takes more time (which would not be feasible given the large number of countries we are dealing with).
} 
way is a frequent identification strategy in the empirical literature based on static discrete models and cross-sectional data (see van Soest, 2005, Blundell et al. 2000). Furthermore, we benefit here from some time and spatial variation that can produce additional exogenous variations in net wages. For seven countries, we dispose of two years of data. The three-year interval between the two corresponding tax-benefit systems, 1998 and 2001, gives us some guarantee that enough exogenous changes in tax-benefit policies occurred over time. Several important reforms indeed took place (e.g., the Working Family Tax Credit reform in the UK, reductions in social security contributions in Belgium and Germany, new tax credit and tax reforms, tax reforms in France, Germany, Ireland, etc., see Orsini, 2006). Notice that consecutive years would provide less exogenous variation but would also make the assumption of constant preferences over time less restrictive. This trade-off is interesting and rarely discussed in the literature. In the next section, we examine the implications of conducting estimations either on pooled years or on each year of data separately.

For most countries, we also have regional variation in tax-benefit rules and, hence, in net wages. This source of identification has been extensively used in the US (variations across states in the income tax code, in benefits rules and the EITC are used in labor supply studies, e.g., Eissa and Hoynes, 2004, Hoynes, 1996, or Meyer and Rosenbaum, 2001). For EU member states, housing benefits vary in almost all countries at the municipality or county level, taking into account local differences in housing costs (exceptions are Belgium, Italy, Portugal and Spain). In Estonia, Hungary and Poland, local governments provide different supplements to almost all benefits, including child benefits/allowances and social assistance. Regional variation in the latter also exists in Denmark, Germany, Italy and Spain. Finally, taxation often varies locally. ${ }^{7}$ The tax-benefit simulators at use and demographic information in our datasets allow us to account for all these differences across households in our sample. Ideally, of course, one would like to gather many years of data for each country to allow for more exogenous variations in net wages (as in Blundell et al., 1998). This is certainly an enormous task when trying to compare many countries and when accounting for complete tax-benefit systems, as we do here. Also, we must acknowledge that the sources of identification are partly different across countries, which

\footnotetext{
${ }^{7}$ County and municipality flat taxes in Nordic countries can vary substantially (ex: $22.8-27.8 \%$ in Denmark; $16.5-21 \%$ in Finland; $29-36 \%$ in Sweden). Regional variations in church tax rates are significant in Finland and Germany. Note that the mere choice of paying church tax is also a relatively exogenous variation across individuals in all countries where it exists. Social insurance contributions can vary by region (e.g., in Germany). Other regional variation exists and concerns tax rates (the Netherlands, Portugal and Spain via imputed rents), tax credits (Belgium), tax deductions (Italy) and council taxes (the UK). Note that for the EU, information on tax-benefit rules for each country is available at: www.iser.essex.ac.uk/research/euromod (together with modeling choices and validation of EUROMOD). For the US, tax-benefit rules (and TAXSIM) are presented in detail at www.nber.org/ $\sim$ taxsim/.
} 
limits the comparability of our results. This issue is obviously not specific to our study. In fact, the degree to which we can compare elasticities across studies, most often based on different identifying assumptions, could be questioned all the same. We believe that the present approach constitutes a reasonable trade-off between comparability attempt and a reasonable identification strategy on cross-sectional data.

Elasticities. In the present nonlinear model, labor supply elasticities cannot be derived analytically but can be calculated by numerical simulations using the estimated model. For wage (income) elasticities, we simply predict the change in average work hours and in participation rates following a marginal uniform increase in wage rates (non-labor income). We have checked that results are similar when wage elasticities are calculated by simulating either a $1 \%$ or a $10 \%$ increase in gross wages (unearned incomes). For couples, cross-wage elasticities are obtained by simulating changes in female hours when male wage rates are increased, and vice versa. For predictions of labor supply effects, baseline estimates rely on the frequency approach, which consists simply of averaging the probability of each discrete choice over all households before and after a change in wage rates or unearned income. In the robustness section, we also report results using the calibration method (Creedy and Kalb, 2005). This approach, consistent with the probabilistic nature of the model at the individual level, consists of repeatedly drawing a set of $J+1$ random terms for each household from an EV-I distribution (together with terms for unobserved heterogeneity), which generate a perfect match between predicted and observed choices. The same draws are kept when predicting labor supply responses to an increase in wages or non-labor income. Averaging individual responses over a large number of draws provides robust transition matrices.

\subsection{Data, Selection and Tax-Benefit Simulations}

Data and Selection. We focus on the US, 14 members of the EU prior to May 1, 2004 (the so-called EU-15 except Luxembourg) and three new member states (NMS), namely Estonia, Hungary and Poland. For each country, we draw from standard household surveys the information about incomes and demographics that can be used for detailed tax-benefit simulations and labor supply estimations (see data source in the third row of Table 5). For the EU-15, the datasets at use have been assembled within the framework of the EUROMOD project (see Sutherland, 2007) and combined with tax-benefit simulations for years 1998, 2001 or both. For the NMS, data were collected for the year 2005, and policies simulated for that year, in a more recent development of the EUROMOD project. For the US, we use the 2006 (Integrated Public Use Microdata Series, IPUMS) Current Population Survey (CPS), which contains information for the year 2005 
as well. Datasets have been harmonized in the sense that similar income concepts are used together with comparable variable definitions. For each country, we extract three samples (couples, single men and women) for the purpose of labor supply estimations. We only keep households where adults are aged between 18 and 59, available for the labor market (not disabled, retired or in education) and we exclude self-employed, farmers and "extreme" situations, including very large families and those who report implausibly high levels of working hours.

Simulations. For each discrete choice $j$ and each household $i$, disposable income $C_{i j}$ is obtained by adding benefits and withdrawing taxes and social contributions to household gross income. These tax-benefit calculations, represented by function $d()$ in expression (2), are performed using information on income and socio-demographics together with tax-benefit simulators. For Europe we use EUROMOD, a calculator designed to simulate the redistributive systems of the EU-15 countries and of some of the NMS. An introduction to EUROMOD, a descriptive analysis of taxes and transfers in the EU and robustness checks are provided by Sutherland (2007). EUROMOD has been used in several empirical studies, notably in the comparison of European welfare regimes by Immervoll et al. (2007, 2011). For the US, tax-benefit calculations are conducted using TAXSIM (version v9), the NBER calculator presented in Feenberg and Coutts (1993), augmented by simulations of social transfers. This calculator is used in combination with CPS data in several applications (e.g, Eissa et al., 2008). ${ }^{8}$ We assume full benefit take-up and tax compliance. More refined estimations accounting for the stigma of welfare program participation would require precise data information on actual receipt of benefits, which is not always available or reliable in interview-based surveys (see Blundell et al., 2000).

Statistics. Descriptive statistics of the selected samples are presented in Table 5. For married women, mean worked hours show considerable variation across countries. This is essentially due to lower labor market participation in Southern countries (with the noticeable exception of Portugal), Ireland and, to a lesser extent, Austria and Poland. The correlation between mean hours and participation rates is .92. There is nonetheless some variation in work hours among participants, with shorter work duration in Austria, Germany, Ireland, the Netherlands and the UK. The participation of single women is lower in Ireland and the UK due to the larger frequency of single mothers (we can see that the average number of children among single women is the highest in these two countries

\footnotetext{
${ }^{8}$ Note that we make use of those policy years available in EUROMOD at the time of writing (1998, 2001 or 2005, as indicated above). For comparison, we use TAXSIM simulations for the year 2005. Hopefully, future developments of the EUROMOD project will allow extending our results to more recent data (and more countries).
} 
and Poland). There is much less variation for men, the main notable fact being lower participation rate for single compared to married men. The variation in wage rates and demographic composition across countries is also noteworthy. In particular for married women, participation rates are correlated with wage rates $(\operatorname{corr}=.36)$ and the number of children (-.61). Attached to these patterns, there may be interesting differences across countries in the responsiveness of labor supply to wages and income. We turn to this central issue in the next sections. In Table 6, we take a closer look at the distribution of actual worked hours. For men, this shows the strong concentration of work hours around full time (35 - 44 hours per week) and non-participation. There is more variations for women, in particular with the availability of part-time work in some countries (another peak at 15-24 hours can be seen in Belgium and the Netherlands, or at 25-34 hours in France where some firms offer a $3 / 4$ of a full-time contract). The US is characterized by a relatively concentrated distribution (around full-time and inactivity) and a relatively high rate of overtime. To accommodate with the particular hour distribution of each country, while maintaining a comparable framework, we suggest a baseline estimation using a 7point discretization, i.e., $J=7$ for singles and $J=7 \times 7$ for couples, with choices from 0 to 60 hours/week (step of 10 hours). We check below the sensitivity of our results to alternative choice sets.

\section{Results}

\subsection{Labor Supply Estimations}

Main Results. Estimated parameters are broadly in line with usual findings and we comment them very briefly. ${ }^{9}$ As expected, the presence of children significantly decreases the propensity to work for women (both women in couples and single mothers) in most countries. Taste shifters related to age are often significant for women in couples but not systematically for other demographic groups. The constant of the cost of work is always significantly positive for all groups. The presence of young children impact most often positively and significantly on the work cost of women. For single men and women, higher education leads to lower costs which can be interpreted as demand-side constraints in the form of lower search costs (see van Soest and Das, 2001).

Fit. Pseudo-R2 convey that the fit is reasonably good: .31 on average for couples (.28 for singles), from .23 for the UK to .45 for Poland (from .16 in Sweden to .40 in Greece for single females and .14 in Sweden to .40 in Belgium for single men). Since pseudo-R2

\footnotetext{
${ }^{9}$ Due to a lack of space, we do not report estimates. Detailed tables with estimates, log-likelihood and pseudo R2 are available from the authors, separately for couples, single women and single men.
} 
cannot be interpreted as standard R2, a more useful measure of the fit consists of the comparison between observed and predicted hours. In Table 7, we first notice that mean hours compare well, as the discrepancy of mean predicted hours is less than $1 \%$ in most of the cases. There are some exceptions, with larger differences especially for women in Portugal, Greece and Spain. For the two latter countries, we report the distribution of observed and predicted frequencies for each choice (here we use $4 \times 4$ choices rather than the $7 \times 7$ baseline, to make it more readable). We can see that the option 11 (both spouses work 40 hours/week) is slightly underestimated while the choice 3 (she does not not work, he works full-time) is overpredicted. Yet, even for these countries, the overall distributions of observed and predicted hours compare well. We have checked for all countries that satisfying comparisons at the mean do not hide wrong hour distributions. We report only two additional graphs for an illustration of the case where mean hours are correctly predicted (France and the Netherlands), confirming that this corresponds to a situation where distributions also compare very well. Finally, we have estimated the baseline model on a random half of the sample for each country and used it to predict hours for the other half. Fit measures on the holdout sample show good results and convey that the flexible model at use does not overfit the data in a way that would reduce external validity.

\subsection{Elasticities}

General Comments. Baseline labor supply elasticities are summarized in Tables 8 and 9 for couples and Tables 10 and 11 for single women and single men respectively. We report own-wage hour elasticities, overall and for quintiles of disposable income, the hour elasticity for the sub-group of participants (the pure intensive margin) and the participation elasticity (the extensive margin), followed by cross-wage hour elasticities and income elasticities. Bootstrapped standard errors are obtained by repeated random draws of the model parameters from their estimated distributions and by recalculating elasticities for each draw. This is computationally demanding and we perform these bootstraps only for the main elasticity results. It transpires that estimates are relatively precise, slightly more for couples than for single individuals. ${ }^{10}$ Results are broadly in line with stylized facts in this literature. Firstly, most of the response to wage changes is due to changes in participation (the extensive margin). The pure intensive elasticities are extremely small for all countries and all demographic groups, for example, lower than .08 for married women in all countries (except the Netherlands). They are sometimes negative for men in

\footnotetext{
${ }^{10}$ This may be due to the fact that there is less variation in labor market behavior among singles (with the exception of lone parents when compared to childless single individuals). Also, the model for couples generally fits the data better because the relatively high level of voluntary inactivity among married women conforms well with the supply-side behavioral assumptions.
} 
couples (Italy and the UK) and for singles (for instance, single men in Belgium, Ireland and Portugal). Reassuringly, the total (own-wage) hour elasticity is close to the sum of the pure intensive elasticity and the participation elasticity in most of the cases. Secondly, own-wage elasticities are the largest for married women and the smallest for married men, as expected. For couples, cross-wage elasticities are negative and smaller than own-wage elasticities, yet nonetheless sizeable for some countries (Austria, Denmark, Germany and Ireland), which is not an usual result (see, e.g., Callan et al., 2009, or Aaberge et al., 2000). As often in the literature, income elasticities are negative and very small in absolute value. Blundell and MaCurdy (1999) report that variation between studies regarding the income elasticity appears to be greater than the corresponding variation with respect to the wage elasticity. We do not confirm much variation as far as "controlled" cross-country comparisons are concerned. In the following, we focus specifically on own-wage elasticities to link our results to the existing literature.

Reconciliation with Past Results. The survey in section 2 conveyed the idea that elasticities are relatively modest when estimated using unconstrained, discrete-choice models (as compared to first generation Hausman models). Our results confirm this trend in a more definitive manner, given the large number of countries under investigation and the common framework at use. Concerning married women, our estimates are very close to, or not statistically different from, past findings for Austria, Belgium, Finland, Germany, Sweden and the UK. ${ }^{11}$ Our estimates are however smaller or close to the lower bound of past confidence intervals for Ireland, Italy and the Netherlands, which is partly explained by the use of older data in the cited studies based on discrete models (e.g., papers by van Soest and coauthors cited in Table 2) or by a different, more general approach where the choice set is extended to hour-wage bundles (see papers by Aaberge, Colombino and coauthors in Table 2). For France, elasticities for married women are smaller than in other studies, which can be attributed to different methods, data and selection as explained above. For Spain, our estimates are relatively large compared to previous evidence, yet the rare studies based on discrete models do not report confidence intervals. Our estimates for the US are very small and compare well to the most recent results (Heim, 2009). US studies which report larger elasticities rely on older data, while it has been shown that elasticities have dramatically decreased over time (Heim, 2007). For other countries, evidence based on discrete models is not directly comparable to our results or simply absent. For other demographic groups, the comparison is even more limited. Our estimates for married men compare well to previous results in countries where

\footnotetext{
${ }^{11}$ For instance for Germany, most studies report median own-wage elasticities of around .3 for married women (with relatively broad confidence intervals), which is similar to our result for the years 1998 and 2001.
} 
significant evidence exist (Belgium, Germany, Ireland, Italy, the Netherlands, Sweden and the US), but comparison points for other countries are generally missing. The situation is similar in the case of single individuals. There is a substantial number of estimates for Germany, with which our results conform well. In the case of single mothers, numerous studies on single mothers are available on the UK and the US. Our results point to more moderate elasticities than in most of these studies, mainly for the data year and methodology reasons discussed above, with the exception of Blundell et al. (1992) for the UK and Dickert et al. (1995) for the US, which report comparable estimates to ours. Our results nicely complete the scattered evidence in the literature by providing a comprehensive and more comparable assessment of EU-US elasticities. We discuss them in detail, before turning back to our initial questions: how do elasticities compare across countries?

New Results and International Comparisons We first focus on married women, the group mostly studied in the literature. For them, hour and participation elasticities are to be found in a very narrow range $.2-.3$ for several countries (Austria, Belgium, Denmark, Germany, Italy and the Netherlands). They are slightly smaller, around .1-.2, but significantly different from zero in France (for 2001), Finland, Portugal, Sweden, the NMS, the UK and the US. They are significantly larger, between .4 and .6, in Ireland, Greece and Spain. Total hour elasticities follow the same pattern. Thus, our results show that elasticities are relatively modest and hold in a narrow interval once comparable datasets, selection and empirical strategies are used. This is an interesting result given the substantial differences that exist across countries in terms of labor market conditions, institutions and preferences/culture. Notice that estimates are sufficiently precise, however, so that differences between the three groups of countries mentioned above are statistically significant. The nature of the remaining differences between countries is investigated in the next section. Note that the simple intuition that elasticities are larger when female participation is lower is broadly confirmed by the data, i.e., the cross-country correlation between mean wage hour (participation) elasticities and mean worked hours (participation rates) is around $-0.81(-0.84)$. For married men, results are even more compressed, with own-wage elasticities usually ranging between around .05 and .15. Estimates are usually significantly larger than zero and precise enough to find statistical differences across some countries, yet less pronounced than for women. The correlation between elasticities and worked hours (participation) is only around $-0.41(-0.64)$. Elasticities for single men show a little more variation, usually in a range between 0 and .3 with a few exceptions (estimates are significantly higher in Ireland and Spain). They are significantly different from zero in most cases with some exceptions including Italy and Portugal. Estimates are slightly larger than for married men overall, which is in line with lower participation rates among singles. We also observe some variation among single women, usually between .1 
and .4 with larger elasticities for some countries (around .6 in Belgium and Italy). The correlation between elasticities and worked hours (participation) among single individuals is usually smaller than for couples: .50 (.50) for women and .32 for men (.46).

Other Dimensions. In Tables 8-11, we provide additional results beyond simple mean elasticities. For single individuals and married men, the distribution of elasticities across income groups (quintiles) shows a clear decreasing pattern, with largest elasticities for low-income groups. In fact, heterogeneous elasticity across different earnings groups is crucial for welfare analysis. Eissa et al. (2008) show that normative conclusions of policy evaluations change completely when recognizing that participation elasticities can be significantly larger at the bottom of the distribution. Very few studies report this kind of information however (see evidence based on structural models in Meghir and Phillips, 2008, for the UK and Aaberge et al., 2002, for Italy). Interestingly, our results generalize their findings for single individuals and, to some extent, for married men. Results for married women do not show such a pattern, which has to do with joint decision in couples - Eissa (1995) also finds that elasticities for married women may still be substantial at the top.

For couples and single women, we also report estimates for those with and without children. In Table 10, we notice that single mothers tend to have larger elasticities than childless women, yet differences are usually not significant. The notable exceptions, with very large elasticities for single mothers, concern Greece and Ireland. The same result is observed for married couples: elasticities are usually larger for women with children, but not markedly. The main exceptions are Greece, Ireland and Spain, i.e., the highelasticity group for married women. ${ }^{12}$ Finally, when two years of data are available, we have reported elasticities based on separate estimations for each year. Time variation is small but seems to coincide with smaller elasticities when participation increases over time. We also find that estimates of the utility function are relatively similar across years, which is reassuring about the fact that preferences do not change substantially over the three-year interval. Yet they may change enough to explain time change in elasticities. As discussed above, identification is improved when two years of data are pooled. In that case, i.e., when assuming identical preferences for the two years, we find almost identical elasticities for the two years, which broadly correspond to the average of the two elasticities reported in Tables 8-11. For instance, we find own-wage elasticities of around .18 for married women in France for both 1998 and 2001. This confirms that time

\footnotetext{
${ }^{12}$ Table 5 shows that the number of couples with children is large in Ireland but close to average in Greece and Spain. Hence, higher elasticities among married women in these countries do not seem to be driven by a higher proportion of families with children but by the higher responsiveness of mothers. This is confirmed by the decomposition analysis in the next section.
} 
differences observed in Tables 8-11 are due to (small) changes in preferences over time rather than other factors like changes in demographic characteristics. This is line with the results of Heim (2007), for the US, over a much longer time period.

\subsection{Robustness Checks}

We have argued that models with discrete choices are very general as they do not require imposing much constraint on preferences and allow accounting for complete tax-benefit policies affecting household budgets. As discussed in Section 2, we may nonetheless check whether our estimates are sensitive to several crucial aspects of the model specification. Results of this extensive robustness check are provided in Tables 12 and 13 where we focus on the own-wage and income elasticities of total hours and participation for married women. Firstly, we simply check the sensitivity to the method used to calculate elasticities. The first row of results corresponds to the baseline, that is, a 7 -choice model with quadratic utility and fixed costs, whereby elasticities are obtained by the frequency method. The second row reports the average elasticity over the 250 draws used to bootstrap standard errors in the baseline model. The third row shows elasticities obtained with the calibration method, as previously defined. Reassuringly, we see very little differences in the three sets of results. Secondly, and more importantly, we check whether the main restriction of the model, i.e., the fact that the choice set is discretized, plays some role. The next rows in each panel report elasticities when alternative choice sets are used, namely a discretization with $4-$ and 13 -hour choices. The model with $J=4$ choices for singles $(4 \times 4=16$ for couples) essentially captures the commonly agreed durations of work: non-participation (0), part-time (20), full-time (40) and overtime (50 hours/week). Such a model does not adapt particularly well to the hour distribution of each country. The narrower discretization with 13 choices, from 0 to 60 hours/week with a step of 5 hours, and $13 \times 13=169$ combinations for couples, is more computationally demanding. However, it may capture more country-specific hour distributions and, in fact, get closer to a continuous specification. Interestingly, Tables 12 and 13 show that results are very similar in all three cases $(J=4,7$ and 13$)$. Only slightly larger elasticities are observed in the 4-point case for some countries (e.g., Belgium and Ireland). Finally, we check whether elasticities are sensitive to the functional form at use. Similar to van Soest et al. (2001) for the Netherlands, we experiment alternative specifications by increasing the order of the polynomial in the utility function: quadratic (baseline) then cubic and quartic. We also change the way flexibility is gained in the model by replacing fixed costs of work, as used in Blundell et al. (2000), by part-time dummies, precisely at the 10, 20 and 30 hour choices, as used in van Soest (1995). These parameters may be interpreted as job search costs for less common working hours (van Soest and Das, 2001), and hence 
include some of the labor market restriction on the choice set. Results for these different specifications are shown in the last rows of each panel in Tables 12 and 13. The size of elasticities hardly changes across the different modeling choices. ${ }^{13}$ This result reinforces our main conclusions regarding international comparison. Given the large number of countries involved, this extensive sensitivity check also adds significantly to the literature by increasing confidence in the use of discrete models.

\section{Assessing the Cross-Country Differences}

The evidence presented above suggests that some cross-country difference in labor supply elasticities remains after controlling for differences in the empirical approach, the sample selection and when focusing on a relatively narrow time period. Fully explaining crosscountry differences in labor supply and labor supply responsiveness is of course beyond the scope of this paper. ${ }^{14}$ In this section, however, we attempt to isolate several important factors. We still focus on married women, primarily because this group shows the most significant variation in elasticities across countries.

\subsection{Wage and Labor Supply Levels}

We have seen that hour and participation elasticities are strongly correlated with mean hour and participation levels across countries. It is possible, then, that larger elasticities in countries like Greece, Ireland and Spain are not due to behavioral parameters but instead to the hour and wage levels that enter the formal definition of elasticities, i.e., $\epsilon_{c}=\frac{\partial H_{c}}{\partial w_{c}} \frac{w_{c}}{H_{c}}$ for country $c$. To probe the effect of these variables and their difference across countries, we compute elasticities as $\epsilon_{c}^{M}=\frac{\partial H_{c}}{\partial w_{c}} \frac{\bar{w}}{\bar{H}}$, using country-specific responsiveness $\frac{\partial H_{c}}{\partial w_{c}}$ and holding hour and wage levels at their mean values over all countries (accounting for PPP differences for wages). We focus on own-wage elasticities of total hours and report the results in Figure 1. The upper left panel compares elasticities in the baseline (circles) and in the "mean levels" scenario (triangular) together with $95 \%$ bootstrapped confidence

\footnotetext{
${ }^{13}$ The only exception seems to be Italy where higher order polynomial utility leads to larger elasticities. The difference with the baseline is statistically significant only in the case of participation elasticities, and partly disappears when we restrict the condition of participation to people working at least five hours a week when calculating elasticities (indeed, there are a number of initial non-working women for whom the predicted number of weekly hours is very small after the wage increase used to calculate elasticities - the additional restriction is reasonable if we consider that it is unusual to observe such small values).

${ }^{14} \mathrm{~A}$ long list of of studies have addressed this issue, sometimes in a more comprehensive manner than in the present framework, for instance by accounting simultaneously for labor supply and fertility choices (e.g., the recent study by Michaud and Tatsiramos, 2011). Yet no definitive answer has been brought to this difficult question of country differences in working time and participation.
} 
intervals. The two scenarios are plotted one against the other in the upper right panel. Lower panels decompose the "mean levels" scenario into two sub-scenarios, one where only hours are hold at the international mean value $\bar{H}$ (lower left) and one where only the mean wage level $\bar{w}$ (lower right) is used. Results show that high-elasticity countries like Greece and Spain are not only characterized by lower female participation but also by lower wage rates, so that these countries remain in the high-elasticity group even in our "mean levels" scenario. This mechanical exercise also pushes Estonia, Hungary and Portugal in the high-elasticity group while it reduce US elasticities to the lowest level. This is clearly due to the fact that the NMS and Portugal (the US) have significant lower (higher) wage rates while their female participation rates are close to the international average. Despite these notable exceptions, the upper right panel of Figure 1 shows that cross-country differences are preserved when elasticities are evaluated at mean values and must therefore be explained by other factors.

\subsection{Tax benefit Systems}

There are many reasons why accounting for tax-benefit policies is important in our study: (i) labor supply estimates are often used to simulate policy reforms; (ii) nonlinearity in effective marginal tax rates and how they vary with individual characteristics (family composition and unearned incomes) aids in identifying the model; (iii) a model ignoring taxes may be misspecified. In addition, the size of hour elasticities may be influenced by differences in tax-benefit systems across countries. Precisely, the responsiveness captured by the derivative $\partial H_{c} / \partial w_{c}$ is calculated in our base estimates by incrementing gross wages by $1 \%$. In this way, the fact that high tax countries, like in the North of Europe, are characterized by smaller net wage increments could explain smaller elasticities. To check this point, we simulate a $1 \%$ increase in the net wage, in order to cancel out differences in effective marginal tax rates (EMTR) across countries due to different tax schedules or benefit withdrawal rates. ${ }^{15}$ Figure 2 reports total hour elasticities in the baseline and in this "net-wage increment" scenario. The right panel plots the two situations while the left panel additionally indicate the $95 \%$ bootstrapped confidence intervals. In general, elasticities after a $1 \%$ increase in net wage are larger - indeed a $1 \%$ changes in gross wages correspond to smaller increments due to taxation. However, and most importantly, crosscountry variation is barely affected when accounting for differences in implicit taxation

\footnotetext{
${ }^{15}$ This is done by retrieving the EMTR on earnings of each individual in the household $\left(t^{f}, t^{m}\right)$ as well as EMTR on unearned income $\left(t^{y}\right)$ using the tax-benefit calculators. In other words, we numerically linearize (2) to express disposable income, for each choice $j$, as $C_{j}=w^{f}\left(1-t^{f}\right) H_{j}^{f}+w^{m}\left(1-t^{m}\right) H_{j}^{m}+\left(1-t^{y}\right) y$. With a truly linear tax system, a $1 \%$ increase in gross and net wage is equivalent. With nonlinear tax systems, we account for the change in $t^{f}$ occurring when gross wage rates are increased, in order to simulate exactly a $1 \%$ increase in the net female wage $w^{f}\left(1-t^{f}\right)$.
} 
of labor income. Since tax-benefit systems can also affect hours and participation, and, in this way, the size of elasticities, we have also simulated a scenario where existing taxbenefit systems are withdrawn completely (or, alternatively, replaced by a uniform flat tax system, which yields similar conclusions). With this counterfactual, the three groups of countries still emerge as the main trend and confirm that "natural" differences exist at least across these broad groups which are not due to tax-benefit institutions.

\subsection{Demographic Characteristics}

We finally turn to the role of demographic composition. As indicated in Section 3.2, important differences exist across countries in this respect, notably the number of children but also the age and education structure. It is plausible that these demographic differences have an effect on the size of elasticities. To investigate this point, we decompose differences in elasticities across countries using an approach similar to that in Heim (2007). Let $i$ denote a woman's age cohort, $j$ her education group and $k$ the number of her children. ${ }^{16}$ Let $\epsilon_{i j k, c}$ denote the wage elasticity of total hours for a woman of type $i j k$ in country $c$. The mean elasticity in this country, $\epsilon_{c}$, can be written as a weighted average $\sum_{i} \sum_{j} \sum_{k} P_{i j k, c} \epsilon_{i j k, c}$, where $P_{i j k, c}$ denotes the proportion of women of type $i j k$ in this country. This proportion can be re-written as $P_{i j k, c}=P_{i, c} P_{j \mid i, c} P_{k \mid i j, c}$ where $P_{i, c}$ denotes the proportion of women in age cohort $i$ in country $c, P_{j \mid i, c}$ the proportion of women in education group $j$ given membership in age cohort $i$, and $P_{k \mid i j, c}$ denotes the proportion of women with $k$ children given membership in age cohort $i$ and education group $j$. Letting $\bar{P}$ denote the mean proportion of a certain type over all countries, the proportion $P_{i j k, c}$ can be expressed as:

$$
\begin{aligned}
P_{i j k, c}= & \bar{P}_{i} \bar{P}_{j \mid i} \bar{P}_{k \mid i j}+\left(P_{i, c}-\bar{P}_{i}\right) \bar{P}_{j \mid i} \bar{P}_{k \mid i j} \\
& +P_{i, c}\left(P_{j \mid i, c}-\bar{P}_{j \mid i}\right) \bar{P}_{k \mid i j}+P_{i, c} P_{j \mid i, c}\left(P_{k \mid i j, c}-\bar{P}_{k \mid i j}\right) .
\end{aligned}
$$

This expression can be used to decompose the mean elasticity where $\bar{\epsilon}_{i j k}$ denotes the mean elasticity for type $i j k$ over all countries:

$$
\begin{aligned}
\epsilon_{c}= & \left(\sum_{i} \sum_{j} \sum_{k} \bar{P}_{i} \bar{P}_{j \mid i} \bar{P}_{k \mid i j} \bar{\epsilon}_{i j k}\right)+\left(\sum_{i} \sum_{j} \sum_{k}\left(P_{i, c}-\bar{P}_{i}\right) \bar{P}_{j \mid i} \bar{P}_{k \mid i j} \bar{\epsilon}_{i j k}\right) \\
& +\left(\sum_{i} \sum_{j} \sum_{k} P_{i, c}\left(P_{j \mid i, c}-\bar{P}_{j \mid i}\right) \bar{P}_{k \mid i j} \bar{\epsilon}_{i j k}\right)+\left(\sum_{i} \sum_{j} \sum_{k} P_{i, c} P_{j \mid i, c}\left(P_{k \mid i j, c}-\bar{P}_{k \mid i j}\right) \bar{\epsilon}_{i j k}\right) \\
& +\left(\sum_{i} \sum_{j} \sum_{k} P_{i, c} P_{j \mid i, c} P_{k \mid i j, c}\left(\epsilon_{i j k, c}-\bar{\epsilon}_{i j k}\right)\right) .
\end{aligned}
$$

\footnotetext{
${ }^{16}$ In our application, we retain three age groups (aged 18-35, 36-45, and 45-59), two education groups and three family sizes (no children, 1-2 children, 3 children or more). Refining with three education groups leads to too many empty cells.
} 
The decomposition starts with the overall mean weighted elasticity, a term common to all countries. The next term denotes how elasticities vary due to the different composition of age cohorts, keeping the distributions of education and family size constant within an age group. The variation in elasticities due to different education levels, keeping the distribution of the number of children within education levels constant, is captured in the third component. The fourth term indicates the difference in elasticities due to different distributions of family size. The last component denotes the difference in elasticities left to be explained by different elasticities within an age-education-children cell, which can be interpreted as a residual difference due to other factors than composition effects (for instance, differences in preferences). The results of this decomposition are presented in Figure 3. We show the deviation of the country-specific elasticities from the mean elasticity that can be attributed to differences pertaining to each of the three demographic factors as well as the residual, unexplained difference. It turns out that differences in demographic composition regarding age and education are never statistically significant. Variation in family size contributes very slightly to larger elasticities in some countries, including Estonia, France, Ireland, Portugal and Spain. Yet these differences are significant only in a few cases, and certainly do not explain the bulk of country differences. Once controlling for these composition effects, the residual term corresponding to "overall" differences in labor supply responsiveness shows a significantly positive effect for Greece, Ireland and Spain (the high-elasticity group) and a significantly negative effect for Finland, France, Sweden, the UK and the US (the low-elasticity group). Therefore, we must conclude that differences in demographic compositions between countries are not responsible for variations in labor supply elasticities. ${ }^{17}$

\subsection{Alternative Explanations}

This leaves room for other explanations. Firstly, there may be genuine differences in work preferences, possibly due to long-lasting differences in culture and the norms vis-avis female labor market participation. Secondly, and in a related way, social preferences may vary across countries and lead to different institutions, notably regarding childcare arrangements. It may be the case that differences in some of the estimated parameters, and in particular the fixed costs of work, reflect country heterogeneity vis-a-vis non-simulated policies like childcare support. Difference in industrial or occupational composition may also play a role, as employment in France and the Nordic countries is often reported to be more stable due to better work-family reconciliation policies. The data at hand do not allow probing such differences across countries and we leave this for

\footnotetext{
${ }^{17}$ We have checked that alternative decomposition paths - given the path dependency of the method give similar results. Similar conclusions are also obtained when using the "net wage" elasticities.
} 
future research. Finally, an explanation in terms of selection can be put forward. We find that marriage rates are significantly higher in high-elasticity countries (the proportion of married women over single women is 6.3 in Ireland or 5.6 in Spain, compared to an average of 3.9 over all countries under study). Hence, it could be that married women in these countries cover a large range of the distribution of elasticities while the relatively smaller fraction of women who marry in France, the Nordic countries, the UK and the US are in the low range of this distribution. If this was the case, one would expect to find larger elasticities among single women in the latter group of countries. Our main results show that it is not the case - the cross-country correlation between elasticities of married and single women is positive (.25) - so this possible explanation can be ruled out.

\section{Conclusions}

The present paper presents new evidence on labor supply elasticities for 17 European countries and the US. Estimates are more comparable than usual results in the literature given the effort of adopting a common empirical approach. The main lesson from the results is that elasticities are more modest than usually thought, and international differences are relatively small. We also show that the remaining variation across countries has little to do with selection into marriage, differences in tax-benefit systems or heterogeneity in demographic composition. It may rather reflect differences in individual and social preferences across countries, and primarily differences in work preferences and childcare policies, as captured by variation in labor supply parameters. As far as married women are concerned, these differences contribute to more intermittent labor force participation patterns in Greece, Ireland and Spain as opposed to more consistent participation and more constant hours in other countries and notably France, the Nordic countries, the UK and the US. This result corroborates the findings of Heim (2007) regarding time variation of elasticities in the US. ${ }^{18}$

Future work should consider both time and country variation. The present study was based on data years for which policy simulations were available within EUROMOD, yet future research should attempt to span a longer period for many countries. Also, a better modeling of demand-side constraints could improve the results, which was not possible with the data at hand. The bias concerns primarily single individuals, for whom the share of involuntarily unemployment is the highest, but not so much married women and single mothers, two groups who frequently choose non-participation on a voluntary basis due to

\footnotetext{
${ }^{18}$ Considering time rather than cross-country variation, Heim (2007) also finds that higher participation rates coincide with much smaller elasticities, and that this trend is not due to demographic changes but more likely to shifts in work preferences.
} 
fixed costs of work and preferences (see Bingley and Walker, 1997, and Bargain et al., 2006, for an extensive analysis of biases affecting elasticities in that case). A more comprehensive measure of elasticities would also account for the interaction between demand and supply (see Peichl and Siegloch, 2010) or for general equilibrium effects.

Despite these restrictions, we believe that the estimates provided in this paper can be useful for researchers who want to implement optimal tax or CGE models in a comparative framework and need to refer to "reasonable" values from the literature (e.g., Jacobs, 2009, on reassessing Prescott's argument). In particular, our results can be exploited for applications in the field of taxation (see also Blundell et al., 2008). Two recent studies, Immervoll et al. (2007 and 2011), have conducted international comparisons of redistributive systems in Europe and their results could be reassessed in the light of the estimates provided in the present study. Firstly, Immervoll et al. (2007) measure the implicit cost of redistribution using plausible elasticities and sensitivity analyses - but without information on actual cross-country differences. Secondly, they assume that participation elasticity decreases with income levels. The implications of this assumption are crucial for welfare analysis (Eissa et al., 2008). Notably, the optimality of policies that support the working poor, compared to traditional "demogrant" policies, depends fundamentally on it. While very limited evidence exists, the present study broadly supports this assumption for single individuals and married men, providing a precise range of estimates for each country. Thirdly, international comparisons of the tax treatment of couples by Immervoll et al. (2011) - essentially the long-studied issue of joint versus individual taxation - could be reevaluated using our new evidence on couples' labor supply elasticities. Related to this point, Heckman (1993) noted "whether labor supply behavior by sex will converge to equality as female labor-force participation continues to increase is an open question". This question has remained open up to now, and the present study contributes to answering it. In fact, we can draw from our results that male-female differentials in participation rates are strongly negatively correlated with male-female differentials in participation elasticities $(\operatorname{corr}=-.89) .{ }^{19}$ Hence, the Ramsey argument against high implicit taxation of secondary earners and the subsequent deadweight loss from joint "effective" taxation which is more frequent than mere joint taxation since many benefits and tax credits are means-tested on household income - can now be assessed on the basis of comparable estimates for many countries.

\footnotetext{
${ }^{19}$ In Nordic countries, the gender participation gap is below 10 points and coincides with insignificant differences in labor supply elasticities. In Spain or Greece, men's participation is still above women's by a large margin (around 50 points) and the gender difference in elasticities is significant and larger than .45. Most EU countries and the US are somewhere between these two extreme cases.
} 


\section{References}

[1] Aaberge, R., J. Dagsvik and S. Strom (1995): "Labor supply responses and welfare effects of tax reforms", Scandinavian Journal of Economics, 97(4), 635-59.

[2] Aaberge, R., U. Colombino and S. Strøm (2000): "Labor supply responses and welfare effects from replacing current tax rules by a flat tax: empirical evidence from Italy, Norway and Sweden", Journal of Population Economics, 13, 4, 595-621.

[3] Aaberge R., Colombino U. and T. Wennemo (2002): "Heterogeneity in the elasticity of labour supply in Italy and some policy implications", WP CHILD \#21/2002.

[4] Andrén, T. (2003): "A Structural Model of Childcare, Welfare, and the Labor Supply of Single Mothers", Labour Economics, 10(2), 133-147.

[5] Ballard, C., J. Shoven and J. Whalley (1985): "General Equilibrium Computations of the Marginal Welfare Costs of Taxes in the United States", American Economic Review, 75(1), pp. 128-137.

[6] Bargain, O. and K. Orsini (2006): "In-work policies in Europe: Killing two birds with one stone?", Labour Economics 13, 667- 697

[7] Bargain, O., Caliendo, M., Haan, P., Orsini, K. (2009): "'Making Work Pay' in a Rationed Labour Market", Journal of Population Economics, 23(1), 323-351

[8] Bingley, P. and I. Walker (1997): "The Labour Supply, Unemployment and Participation of Lone Mothers in In-Work Transfer Programmes", Economic Journal, $107,1375-1390$

[9] Blau, F. and L. Kahn (2007): "Changes in the Labor Supply Behavior of Married Women: 1980-2000". Journal of Labor Economics, 25, pp. 393-438.

[10] Blomquist, S., and U. Hansson-Brusewitz (1990): "The Effect of Taxes on Male and Female Labor Supply in Sweden", Journal of Human Resources, 25, 317-357.

[11] Blundell, R., Duncan, A. and Meghir, C. (1998): "Estimating Labour Supply Responses Using Tax Reforms", Econometrica 66(4)(4): 827-861.

[12] Blundell, R. and T. MaCurdy (1999): "Labor Supply: A Review of Alternative Approaches", in Ashenfelter and Card (eds), Handbook of Labor Economics , vol.3A, ch.27, Elsevier North-Holland.

[13] Blundell, R., A. Duncan, J. McCrae and C. Meghir (2000): "The Labour Market Impact of the Working Families' Tax Credit", Fiscal Studies, 21, 1, 75-103.

[14] Blundell, R., M. Brewer, P. Haan and A. Shephard (2008): "Optimal income taxation of lone mothers: an empirical comparison for Germany and the UK", Economic Journal, 119, 535, 101-121 
[15] Bourguignon, F. and T. Magnac (1990): "Labour supply and taxation in France", Journal of Human Resources, 25, 358-389.

[16] Bovenberg, A. L., J.J. Graafland and R.A. de Mooij (2000): "Tax reform and the Dutch labor market : an applied general equilibrium approach", Journal of Public Economics, 78, 193-214.

[17] Bishop, K., B. Heim, K. Mihaly(2009): "Single Women's Labor Supply Elasticities: Trends and Policy Implications," Industrial and Labor Relations Review, 63(1), 146-168

[18] Brink, A., K. Nordblom and R. Wahlberg (2007) "Maximum Fee versus Child Benefit: A Welfare Analysis of Swedish Child-Care Fee Reform", International Tax and Public Finance, Vol.14 (4), 457-480.

[19] Callan, T., A. van Soest, J. Walsh (2009): "Tax Structure and Female Labour Supply: Evidence from Ireland", Labour, 23(1), 1-35

[20] Chetty, R., J. Friedman, T. Olsen and L. Pistaferri (2009): "The effect of adjustment costs and institutional constraints on labor supply elasticities: evidence from Denmark", Working Paper.

[21] Choné, P., D. Le Blanc and I. Robert-Bobée (2003): "Female labor supply and child care in France", CREST working paper.

[22] Clauss, M. and R. Schnabel (2006): "Distributional and Behavioural Effects of the German Labour Market Reform", ZEW working paper.

[23] Creedy, J. and G. Kalb (2005): "Discrete hours labour supply modelling: specification, estimation and simulation", Journal of Economic Surveys, 19(5), 697-733

[24] Crespo, L. (2006): "Estimation and Testing of Household Labour Supply Models: Evidence from Spain", mimeo

[25] Dearing, H., H. Hofer, C. Lietz, R. Winter-Ebmer, K. Wrohlich (2007): "Why Are Mothers Working Longer Hours in Austria than in Germany? A Comparative Microsimulation Analysis", Fiscal Studies, 28 (4), 463-495

[26] Devereux, P. (2004): "Changes in Relative Wages and Family Labor Supply", Journal of Human Resources, 39, 696-722.

[27] Dickert, S., S. Houser and J.K. Scholz (1995): "The Earned Income Tax Credit and Transfer Programs: A Study of Labor Market and Program Participation." in J. Poterba (ed.), Tax Policy and the Economy 9th ed., 1-50.

[28] Duncan, A. and M. N. Harris (2002): "Intransigencies in the Labour Supply Choice", Melbourne Institute Working Paper No 17/02, 
[29] Eissa, N. (1995). Taxation and Labour Supply of Married Women: The Tax Reform Act of 1986 as a Natural Experiment. NBER Working Paper No. 5023

[30] Eissa, N. and H. W. Hoynes (2004): "Taxes and the labor market participation of married couples: the earned income tax credit," Journal of Public Economics, vol. 88 (9-10), pages 1931-1958.

[31] Eissa, N. and Liebman, J. (1996): "Labor supply response to the earned income tax credit", Quarterly Journal of Economics 111(2): 605-637.

[32] Eissa, N., H. J. Kleven, C.T. Kreiner (2008): "Evaluation of Four Tax Reforms in the United States: Labor Supply and Welfare Effects for Single Mothers", Journal of Public Economics 92, 795-816

[33] Evers, M., R. de Mooij, D. van Vuuren (2008): "The wage elasticity of labour supply: a synthesis of empirical estimates", De Economist, 156:25-43

[34] Feenberg, D. and E. Coutts (1993): "An Introduction to the TAXSIM Model", Journal of Policy Analysis and Management, 12(1)

[35] Fernández-Val, I. (2003): "Household Labor Supply: Evidence for Spain", Investigaciones Económicas, 27(2), 239-275.

[36] Flood, L., J. Hansen \& R. Wahlberg (2004): "Household Labour Supply and Welfare Participation in Sweden", Journal of Human Ressources, 39 (4), 1008-1032.

[37] Fuchs, V.R., A. B. Krueger and J. M. Poterba (1998): "Economists' Views about Parameters, Values, and Policies: Survey Results in Labor and Public Economics", Journal of Economic Literature, 36(3), 1387-1425

[38] García, I. and M.J. Suárez (2003): "Female labour supply and income taxation in Spain: The importance of behavioural assumptions and unobserved heterogeneity specification", Revista de Economía Pública, 164(1): 9-27

[39] Hausman, J. (1981): "Labor Supply", in How Taxes Affect Economic Behavior, ed.H. Aaron and J.Pechman, The Brookings Institution, Washington D.C., 27-72.

[40] Hausman, J. (1985): "Taxes and labour Supply" in Handbook of Public Economics, ed. Auerbach and Feldstein, Amsterdam, North-Holland.

[41] Heckman, J. (1993): "What has be learned about the labor supply in the past twenty years", American Economic Review, Papers and Proceedings, 83, 116-121.

[42] Heim, B. and B. Meyer (2003): "Work costs and nonconvex preferences in the estimation of labor supply models", Journal of Public Economics, 88(11)2323-38

[43] Heim, B. (2007): "The Incredible Shrinking Elasticities: Married Female Labor Supply, 1978-2002." Journal of Human Resources 42(4): 881-918. 
[44] Heim, B. (2009): "Structural Estimation of Family Labor Supply with Taxes: Estimating a Continuous Hours Model Using a Direct Utility Specification." Journal of Human Resources 44(2): 350-385.

[45] Hoynes, H. W. (1996): "Welfare transfers in two-parent families: Labor supply and welfare participation under AFDC-UP", Econometrica, 64(29), 295-332.

[46] Immervoll, H., H. J. Kleven, C. T. Kreiner and E. Saez (2007): "Welfare reform in European countries: a microsimulation analysis", Economic Journal, 117, 1 - 44.

[47] Immervoll, H., H. J. Kleven, C. T. Kreiner and N. Verdelin (2011): "An Evaluation of the Tax-Transfer Treatment of Married Couples in European Countries", forthcoming, Journal of Public Economics.

[48] Jacobs, B. (2009): "Is Prescott right? Welfare state policies and the incentives to work, learn, and retire", International Tax Public Finance, 16: 253-280

[49] Killingsworth, M., and J. Heckman (1986): "Female labor supply: a survey". In: O. Ashenfelter and R. Layard, eds., Handbook of Labor Economics, vol. I, NorthHolland, Amsterdam, pp.103-204.

[50] Kimmel, J. and T. J, Kniesner (1998): "New Evidence on Labor Supply: Employment Versus Hours Elasticities by Sex and Marital Status." Joumal of Monetary Economics 42(2), 289-30L

[51] Kydland, F. E. (1995): "Business Cycles and Aggregate Labor Market Fluctuations," In Frontiers of Business Cycle Research, ed. Thomas F, Cooley, 126-56. Princeton. N. J.: Princeton University Press.

[52] Labeaga, J.M., X. Oliver and A. Spadaro (2008): "Discrete choice models of labour supply, behavioural microsimulation and the Spanish tax reform", Journal of Economic Inequality, 6(3), 247-273.

[53] Laroque, G. and B. Salanié (2001): "Labor market, institutions and employment in France", Journal of Applied Econometrics, 17, 25-48.

[54] MaCurdy, T., P. Green, and H. Paarsch (1990): "Assessing Empirical Approaches for Analyzing Taxes and Labor Supply", Journal of Human Resources, 25, 415-490.

[55] Meghir, C. and D. Phillips (2008): "Labour Supply and Taxes", Institute for Fiscal Studies, WP 08/04.

[56] Meyer, B. and Rosenbaum, D. (2001): "Welfare, the earned income tax credit, and the labor supply of single mothers", Quarterly Journal of Economics 116(3): $1063-1114$. 
[57] Moffitt, R. (1990), Introduction to the Special Issue on Taxation and Labor Supply in Industrial Countries, Journal of Human Resources, 25(3), 313-316

[58] Orsini, K. (2006): "Tax benefit reforms and the labor market: Evidence from Belgium and other EU countries", Leuven University, working paper.

[59] Peichl, A. and Siegloch, S. (2010): "Accounting for Labor Demand Effects in Structural Labor Supply Models", IZA Discussion Paper 5350.

[60] Pencavel, J.H. (1986): "Labor supply of men: a survey", in O. Ashenfelter and R. Layard (eds), Handbook of Labor Economics, vol.1, Amsterdam, North-Holland.

[61] Prescott, E.C. (2004): "Why do Americans work so much more than Europeans?," Quarterly Review, Federal Reserve Bank of Minneapolis, issue Jul, 2-13.

[62] Saez, E. (2001): "Using elasticities to derive optimal income taxe rates", Review of Economic Studies, 68, 205-229.

[63] Smith, N., S. Dex, J.D. Vlasblom and T. Callan (2003): "The effects of taxation on married women's labour supply across four countries", Oxford Economic Papers, $55,3,417-439$

[64] Sutherland, H. (2007): "Euromod: the tax-benefit microsimulation model for the European Union", in A. Gupta and A. Harding (eds), Modelling Our Future: Population Ageing, Health and Aged Care, Vol. 16 of International Symposia in Economic Theory and Econometrics, Elsevier, pp. 483-488.

[65] Michaud, P.-C. and K. Tatsiramos (2011): "Fertility and Female Employment Dynamics in Europe: The Effect of Using Alternative Econometric Modeling Assumptions", forthcoming in Journal of Applied Econometrics

[66] Train, K. (2003). Discrete Choice Models using Simulation. Cambridge, UK: Cambridge University Press.

[67] van Soest, A. (1995): "Structural Models of Family Labor Supply: a Discrete Choice Approach", Journal of Human Resources, 30, 63-88.

[68] van Soest, A. and M. Das (2001): "Family labor supply and proposed tax reforms in the Netherlands", De Economist, 149(2), 191-218.

[69] van Soest, A., M. Das and X.Gong (2001): "A structural labor supply model with non-parametric preferences", Journal of Econometrics (Annals), 107, 345-374. 

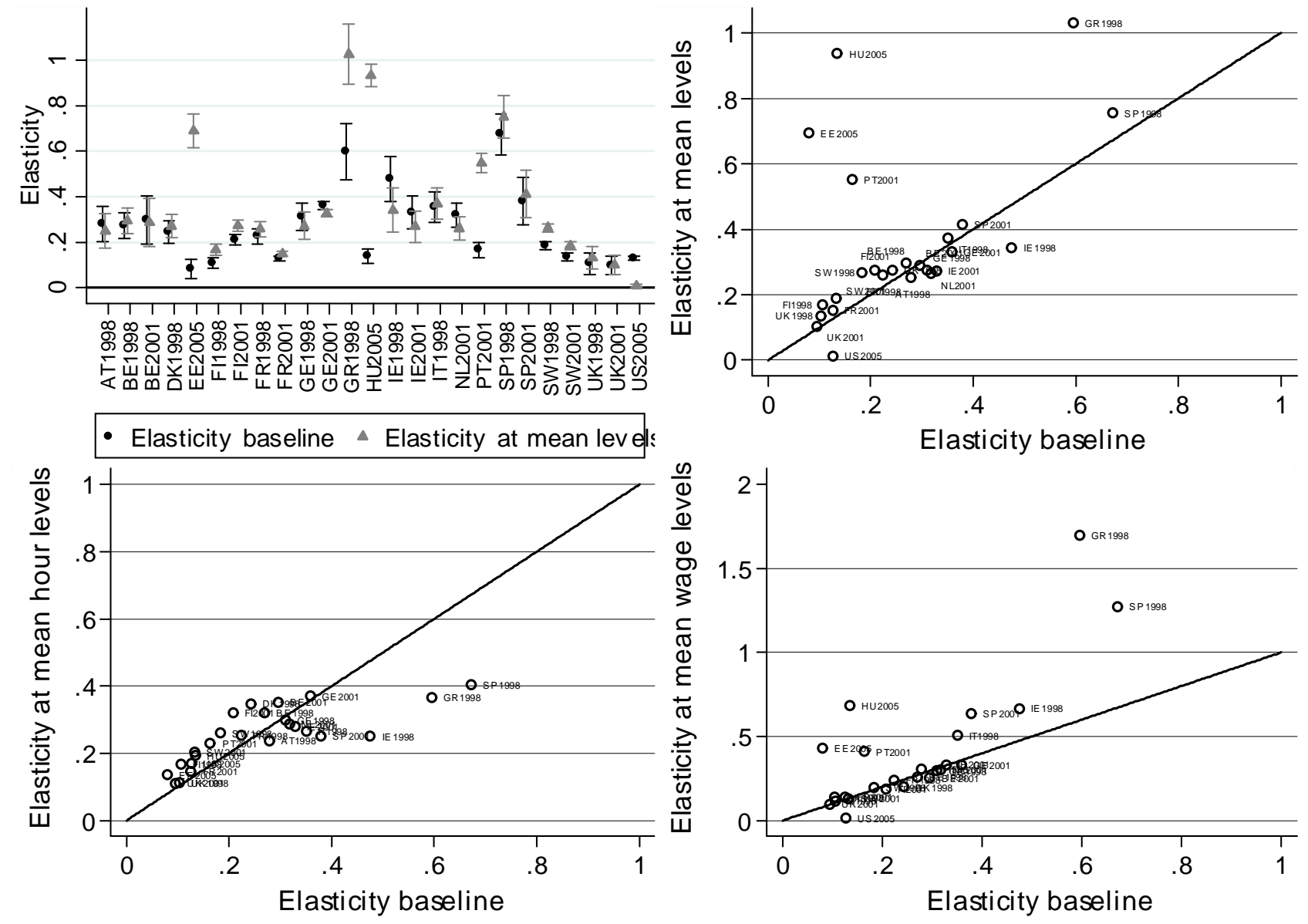

Figure 1: Effect of Wage and Hour Levels on Wage-Elasticities of Total Hours (Married Women) 

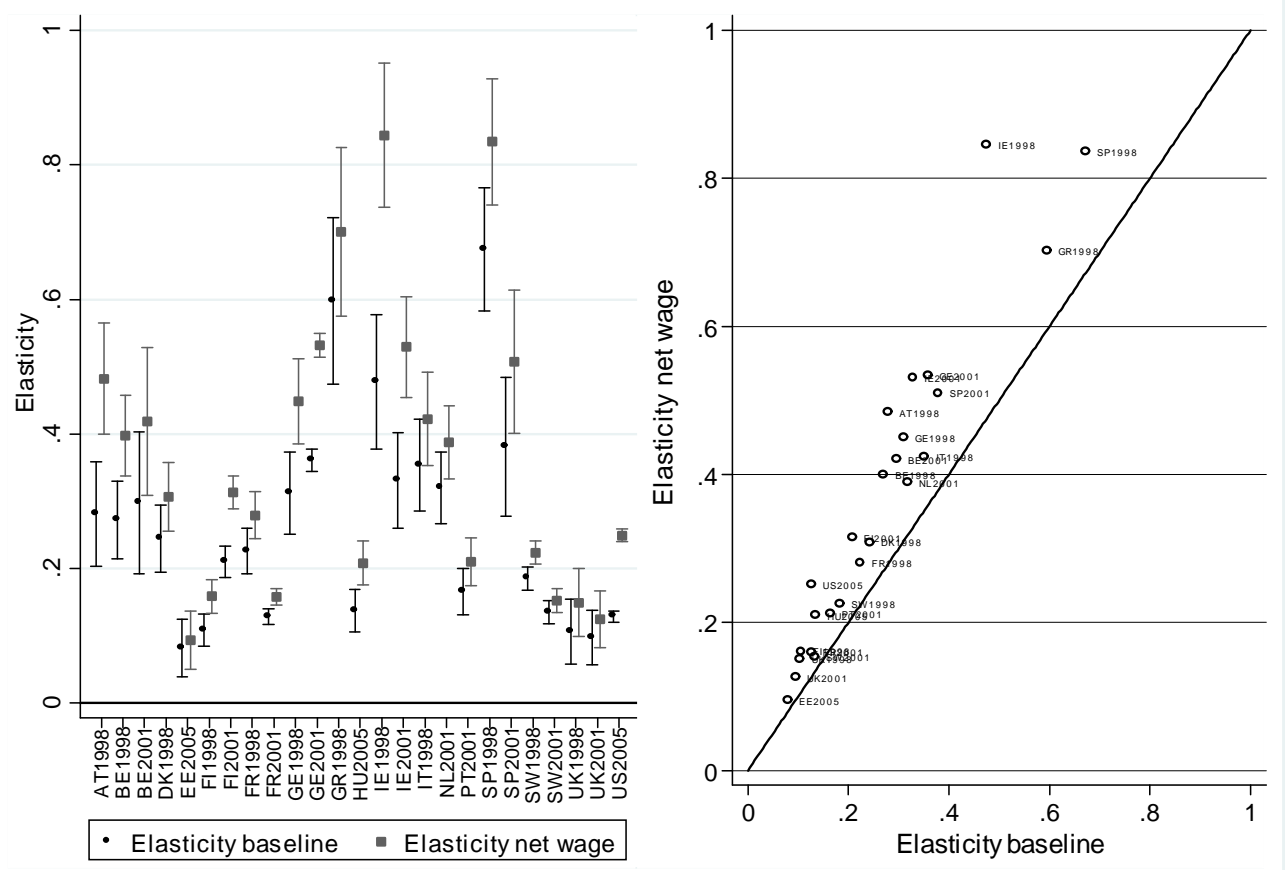

Figure 2: Effect of Tax-benefit Systems on Wage-Elasticities of Total Hours

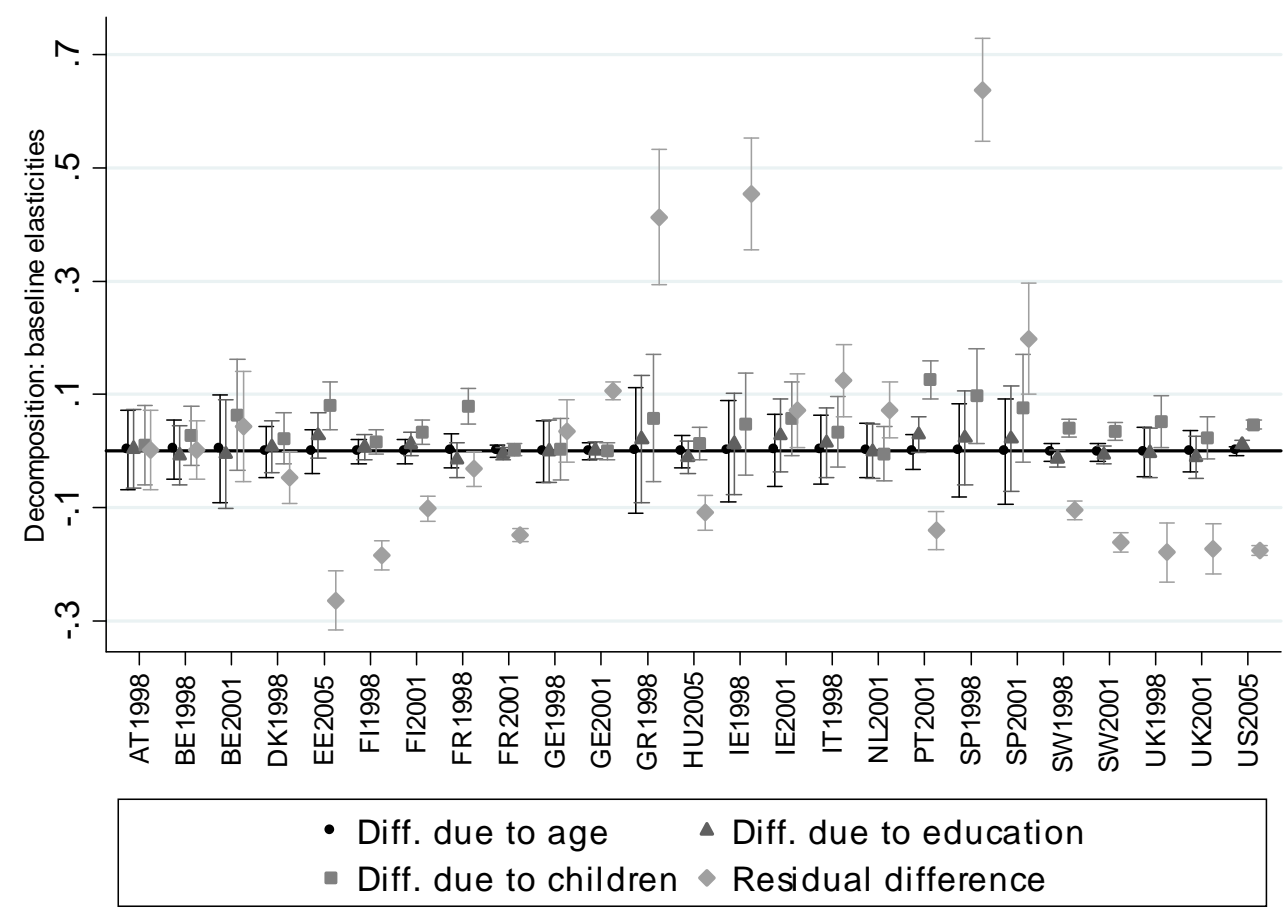

Figure 3: Deviation to the Mean Hour Elasticity due to Demographic Characteristics 


\section{Table 1: Labor Supply Elasticities in Europe: Couples}

\begin{tabular}{|c|c|c|c|c|c|c|c|c|c|c|c|}
\hline \multirow{2}{*}{ Country } & \multirow{2}{*}{ Authors } & \multirow{2}{*}{ Data selection } & \multirow{2}{*}{ Model } & \multirow{2}{*}{ Specification } & \multirow{2}{*}{ Tax-benefit } & \multicolumn{2}{|c|}{ Female wage elast. } & \multicolumn{2}{|c|}{ Male wage elast. } & \multicolumn{2}{|c|}{ Income elast. } \\
\hline & & & & & & hours & particip. & hours & particip. & female & male \\
\hline Austria & Dearing et al. (2007) & SILC (2004), at least 1 child aged $<10$ & $\mathrm{D}$ & QU; M & ITABENA & & {$[.07, .19] @$} & & & & \\
\hline Belgium & Orsini $(2006,2007) \$$ & $\begin{array}{l}\text { Panel Survey of Belgian Households } \\
\text { (2001), working age }\end{array}$ & $\mathrm{D}$ & QU and GU + PTD; J & MODETE & {$[.16, .31]$} & {$[.10, .19]$} & {$[.10, .18]$} & {$[.08, .15]$} & & \\
\hline \multirow[t]{2}{*}{ Finland } & Kuismainen $(1997) \S \#$ & LFS (1989), survey \& tax register; 25-60 & $\mathrm{C}$ & SL, R & PL & {$[0, .06]$} & & & & {$[.11, .27]$} & \\
\hline & Bargain \& Orsini (2006) \$ & $\begin{array}{l}\text { IDS (1998), working age, men all } \\
\text { employed }\end{array}$ & $\mathrm{D}$ & $\mathrm{QU}+\mathrm{FC} ; \mathrm{M}$ & EUROMOD & {$[.10, .18]$} & {$[.10, .17]^{*}$} & & & & \\
\hline \multirow[t]{5}{*}{ France } & 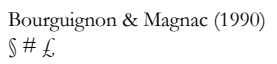 & LFS (1985), couples aged 18-60 & $\mathrm{C} / \mathrm{T}$ & $\mathrm{LL}+\mathrm{R} ; \mathrm{M}$ or J & PL, D & $\begin{array}{l}1 \text { (.05 with } \\
\text { FC) }\end{array}$ & & .10 & & $\begin{array}{l}-.03(-.02 \\
\text { with FC) }\end{array}$ & -.07 \\
\hline & Laroque \& Salanie (2002) & $\begin{array}{l}\text { matched LFS-Tax returns (1999), } \\
\text { women aged } 25-49\end{array}$ & $\mathrm{D}$ & $\begin{array}{l}\text { joint particip. \& wage; } \\
\text { unempl. \& min. wage }\end{array}$ & own calc. & & $(.96)$ & & & / -..11* & \\
\hline & $\begin{array}{l}\text { Choné, Le Blanc \& Robert- } \\
\text { Bobée(2003) }\end{array}$ & $\begin{array}{l}\text { matched LFS-Tax returns }(1997) \text {, } \\
\text { working age, children aged }<6\end{array}$ & $\mathrm{D}$ & $\begin{array}{l}\text { QU, joint wage \& } \mathrm{CC} \text {; } \\
\text { min. wage }\end{array}$ & own calc. & 1.05 & {$[.8, .9] @$} & & & $-.19 /-.18^{*}$ & \\
\hline & Bargain \& Orsini (2006) \$ & $\begin{array}{l}\text { HBS }(1994 / 5) \text {, working age women, } \\
\text { men all employed }\end{array}$ & $\mathrm{D}$ & $\mathrm{QU}+\mathrm{FC} ; \mathrm{M}$ & EUROMOD & {$[.52, .65]$} & {$[.46, .58]^{*}$} & & & & \\
\hline & Donni \& Moreau (2007) & $\begin{array}{l}\text { HBS (2001), aged 20-60, all employed, } \\
\text { no children aged }<3\end{array}$ & $\mathrm{C}$ & $\begin{array}{l}\text { QL; s-conditional } \\
\text { collective LS }\end{array}$ & no taxation & {$[.24, .59]$} & & & & {$[-.35,-.06]$} & \\
\hline \multirow[t]{10}{*}{ Germany } & Kaiser et al. (1992) $₫ \mathcal{E}$ & SOEP (1983), working age & C & LL & C, NC, D & 1.04 & & -.04 & & -.18 & -.28 \\
\hline & $\begin{array}{l}\text { Bonin, Kempe \& Schneider } \\
\text { (2002) \# \$ }\end{array}$ & SOEP (2000), working age, W \& E & $\mathrm{D}$ & TL + PTD; J & IZAmod & .27 & .20 & .21 & .19 & $.15 / .09$ & $.01 / 0$ \\
\hline & Steiner \& Wrohlich (2004) \$ & SOEP (2002), working age, W \& E & $\mathrm{D}$ & TU + PTD; J & STSM & {$[.16, .55] @$} & {$[.07, .21] @$} & {$[.11, .38] @$} & {$[.07, .23] @$} & & \\
\hline & Haan \& Steiner (2005) \$ & $\begin{array}{l}\text { SOEP (2002), working age, W \& E, one- } \\
\text { or two-earner couples }\end{array}$ & $\mathrm{D}$ & TU + PTD; J & STSM & {$[.08, .56]$} & {$[.04, .20]$} & {$[.08, .46]$} & {$[.07, .26]$} & & \\
\hline & Bargain \& Orsini (2006) \$ & $\begin{array}{l}\text { SOEP (1998), working age, men all } \\
\text { employed, W \& E }\end{array}$ & $\mathrm{D}$ & $\mathrm{QU}+\mathrm{FC} ; \mathrm{M}$ & EUROMOD & {$[.31, .45]$} & {$[.27, .38]^{*}$} & & & & \\
\hline & Clauss \& Schnabel (2006) & SOEP $(2004 / 5)$, couples aged 20-65 & $\mathrm{D}$ & TU; J & STSM & .37 & .14 & .24 & .16 & & \\
\hline & Wrohlich (2006) & SOEP (2002), working age, W \& E & $\mathrm{D}$ & TU; J; CC & STSM & {$[.14, .53] @$} & {$[.06, .16] @$} & & & & \\
\hline & Dearing et al. (2007) & $\begin{array}{l}\text { SOEP (2004), at least } 1 \text { child aged }<10 \text {, } \\
\text { W }\end{array}$ & $\mathrm{D}$ & QU; M & STSM & & {$[.13, .24] @$} & & & & \\
\hline & Bargain et al. (2009) & $\begin{array}{l}\text { SOEP (2003), working age, potential one- } \\
\text { or two-earner }\end{array}$ & $\mathrm{D} / \mathrm{H}$ & $\mathrm{QU}+$ PTD, R; J & STSM & {$[.19, .34]$} & {$[.08, .20]$} & {$[.05, .08]$} & {$[.04, .13]$} & & \\
\hline & Fuest et al. (2008) \# & $\begin{array}{l}\text { SOEP (2004), working age, W \& E, } \\
\text { potential one- or two-earner }\end{array}$ & $\mathrm{D}$ & TU+PTD;J & FiFoSiM & 0.38 & 0.15 & 0.20 & 0.14 & & \\
\hline
\end{tabular}

Authors: for references, see $₫$ Blundell and MaCurdy (1999), \# Evers et al. (2008), £, Meghir and Phillips (2008), \$ Orsini (2006)

Data: Income Distribution Survey (IDS), Household Budget Survey (HBS), Socio Economic Panel (SOEP), Family Expenditure Survey (FES), Labor Force Survey (LFS), EU Statistics on Income and Living Conditions (SILC). For Germany: West (W), East (E).

Model: C = continuous labor supply (Hausman 1981 type); $\mathrm{T}$ = tobit model; D = discrete-choice model (van Soest 1995 type); A = estimation of joint distributions of wage and hours (sets of hour-wage opportunities vary across individuals); $\mathrm{H}=$ double hurdle model (labor supply and risk of unemployment).

Specification: for Hausman model, labor supply is either linear (LL), quadratic (QL) or semi-log (SL); in discrete-choice models, utility is either quadratic (QU), translog (TU) or generalized Stone-Geary (GU); random preferences are sometimes accounted for (R) as well additional flexibility, either through fixed costs (FC) or part-time dummies (PTD). Models are male-chauvinistic (M) or account for joint decision in couples (J). Welfare programme participation (W). Childcare costs (CC).

Tax-benefit: Hausman model often accounts for piecewise-linear budget set (PL) or more generally convex set (C); nonconvexities are sometimes accounted for (NC); differentiability of the budget function can be used (D); with discrete choice models, complete tax-benefit systems are simulated and we indicate the name of the microsimulation model when it is known.

Elasticities: brackets indicate the range of values for all specifications (or the confidence interval when available). ' $($ ) indicates that the range also includes values for different age and number of children. Particip. = participation elasticities, corresponding to the increase in employment rate in $\%$ points, except when indicated by * (in that case, $\%$ increase in employment rate). 
Table 2: Labor Supply Elasticities in Europe: Couples (cont.)

\begin{tabular}{|c|c|c|c|c|c|c|c|c|c|c|c|}
\hline \multirow{2}{*}{ Country } & \multirow{2}{*}{ Author } & \multirow{2}{*}{ Data selection } & \multirow{2}{*}{ Model } & \multirow{2}{*}{ Specification } & \multirow{2}{*}{ Tax-benefit } & \multicolumn{2}{|c|}{ Female wage elast. } & \multicolumn{2}{|c|}{ Male wage elast. } & \multicolumn{2}{|c|}{ Income elast. } \\
\hline & & & & & & hours & particip. & hours & particip. & female & male \\
\hline \multirow[t]{2}{*}{ Ireland } & Callan \& van Soest (1996) & IDS (1987), desired hours & $\mathrm{D} / \mathrm{H}$ & $\mathrm{TU}+\mathrm{FC}, \mathrm{R} ; \mathrm{J}$ & SWITCH & {$[.50, .85]$} & $.31 / .20^{*}$ & {$[.10, .20]$} & & & \\
\hline & $\begin{array}{l}\text { Callan, van Soest \& Walsh } \\
(2009)\end{array}$ & $\begin{array}{l}\text { Living in Ireland Survey (1995), desired } \\
\text { hours }\end{array}$ & $\mathrm{D}$ & $\mathrm{TU}+\mathrm{FC}, \mathrm{R} ; \mathrm{J}$ & SWITCH & {$[.71, .90]$} & .49 & {$[.21, .31]$} & $.20 / .21 *$ & & \\
\hline \multirow[t]{3}{*}{ Italy } & $\begin{array}{l}\text { Colombino \& Del Boca } \\
(1990) \S \#\end{array}$ & $\begin{array}{l}\text { Turin Survey of Couples (1979), working } \\
\text { age }\end{array}$ & $\mathrm{C}$ & LL & PL & 1.18 & .64 & & & .52 & \\
\hline & Aaberge et al. (1999) $\mathbb{\&} \mathcal{E}$ & $\begin{array}{l}\text { Survey of Income and Wealth (1987), aged } \\
20-70\end{array}$ & A & $\begin{array}{l}\text { non-linear hours, exog. } \\
\text { wage and unearned inc. }\end{array}$ & own calc. & .74 & .65 & .053 & .046 & / -.014 & $/-.003$ \\
\hline & Aaberge et al. $(2002,04)$ & Survey of Income and Wealth (1993) & A & GU; J & own calc. & .66 & .51 & .12 & .02 & & \\
\hline \multirow[t]{4}{*}{ Netherlands } & van Soest et al. (1990) $§ \#$ & Labor mobility survey (1985), working age & $\mathrm{C} / \mathrm{D}$ & $\begin{array}{l}\text { LL, R; discrete wage-hours } \\
\text { combinations }\end{array}$ & PL & {$[.35, .59]$} & .12 & {$[.15, .19]$} & & -.23 & -.01 \\
\hline & van Soest (1995) §\# & SOEP (1987) & $\mathrm{D}$ & TU + PTD, R; J & own calc. & {$[.42, .54]$} & - & {$[.05, .09]$} & - & .008 & -.03 \\
\hline & van Soest \& Das (2001)\$ & SOEP (1995), aged 16-64, desired hours & $\mathrm{D}$ & $\mathrm{TU}+\mathrm{FC}, \mathrm{R} ; \mathrm{J}$ & own calc. & {$[.67, .74]$} & - & {$[.07, .10]$} & - & & \\
\hline & van Soest et al. (2002) \# & $\begin{array}{l}\text { Dutch SOEP (1995), aged 16-64, desired } \\
\text { hours }\end{array}$ & $\mathrm{D}$ & $\begin{array}{l}\text { QU (+ more flexible) + } \\
\text { FC, R; simult. wage } \\
\text { estimation, J }\end{array}$ & own calc. & {$[.83,1.36]$} & {$[.35, .58]^{*}$} & & & & \\
\hline \multirow[t]{4}{*}{ Spain } & García and Suárez (2003) & $\begin{array}{l}\text { ECHP (1994-95), aged 16-65, obs. and } \\
\text { desired hours }\end{array}$ & $\mathrm{C}$ & LL & taxes & .37 & $1.51^{*}$ & & & -.06 & \\
\hline & Fernández-Val (2003) & ECHP (1994-99), aged <65 and in work & $\mathrm{C}$ & unitary/collective model & no taxation & .31 & & & & & \\
\hline & Crespo (2006) & ECHP (1994-99), aged $<65$ and in work & $\mathrm{C}$ & QL, unitary/collective & no taxation & .14 & & .01 & & & \\
\hline & $\begin{array}{l}\text { Labeaga, Oliver \& Spadaro } \\
(2008)\end{array}$ & ECHP (1995), working age & $\mathrm{D}$ & $\mathrm{QU}+\mathrm{FC} ; \mathrm{J}$ & $\begin{array}{l}\text { GLAD- } \\
\text { HISPANIA }\end{array}$ & .29 & .26 & .01 & .11 & & \\
\hline \multirow[t]{6}{*}{ Sweden } & Blomquist (1983) §\# & $\begin{array}{l}\text { Level of Living Survey (1974), all } \\
\text { employed, aged 25-55 }\end{array}$ & $\mathrm{C}$ & LL, R & PL & & & .008 & & & -.03 \\
\hline & $\begin{array}{l}\text { Flood \& MaCurdy (1992) } \mathbb{S} \\
\# £\end{array}$ & $\begin{array}{l}\text { Household Market-Nonmarket Survey } \\
\text { (1983), all employed, 25-65 }\end{array}$ & $\mathrm{C}$ & LL and SL, R & PL, D & & & {$[-.25, .21]$} & & & {$[-. .01, .04]$} \\
\hline & $\begin{array}{l}\text { Blomquist \& Hansson- } \\
\text { Brusewitz (1990) } \mathbb{\#} f\end{array}$ & $\begin{array}{l}\text { Level of Living Survey (1981), all } \\
\text { employed, aged 25-55 }\end{array}$ & $\mathrm{C}$ & LL and QL, R & PL, $\mathrm{C}$ and $\mathrm{NC}$ & {$[.38, .77]$} & & {$[.08, .13]$} & & {$[-.24,-.03]$} & \\
\hline & $\begin{array}{l}\text { Blomquist \& Newey (2002) } \\
\# £\end{array}$ & $\begin{array}{l}\text { Level of Living Survey }(1973,80,90) \text {, all } \\
\text { employed, aged } 18-60\end{array}$ & $\mathrm{C}$ & $\begin{array}{l}\text { non-parametric labor } \\
\text { supply }\end{array}$ & PL & & & {$[.04, .12\}$} & & & -.02 \\
\hline & $\begin{array}{l}\text { Flood, Hansen \& Wahlberg } \\
\text { (2004) }\end{array}$ & $\begin{array}{l}\text { Household Income Survey (1993), aged 18- } \\
64\end{array}$ & $\mathrm{D}$ & TU, R; stigma of W & own calc. & .12 & & 0 & & -0.017 & -0.003 \\
\hline & Brink et al. (2007) & $\begin{array}{l}\text { Longitudinal Individual Data, Income } \\
\text { Distribution Survey, } 1999\end{array}$ & $\mathrm{D}$ & TU, R & FASIT & .18 & .15 & .06 & 0 & & \\
\hline \multirow[t]{6}{*}{$U K$} & $\begin{array}{l}\text { Arellano \& Meghir (1992) \# } \\
\text { \&. }\end{array}$ & $\begin{array}{l}\text { British FES and LFS (1983), aged 20-59, } \\
\text { with pre-school children (upper bound for } \\
\text { all children) }\end{array}$ & $\mathrm{C}$ & $\begin{array}{l}\mathrm{SL}+\mathrm{FC} \text {, search costs, } \\
\text { endogenous wage and } \\
\text { unearned income (IV) }\end{array}$ & PL & {$[.29, .71]$} & - & & & {$[-.13,-.40]$} & \\
\hline & $\begin{array}{l}\text { Arrufat \& Zabalza (1986) } \mathbb{S} \\
\# \mathcal{E}\end{array}$ & $\begin{array}{l}\text { British General Household Survey (1974), } \\
\text { aged }<60\end{array}$ & $\mathrm{C}$ & $\begin{array}{l}\text { CES utility based labor } \\
\text { supply, R }\end{array}$ & PL & {$[.62-2.03]$} & 1.41 & & & $-.2 /-.14$ & \\
\hline & Blundell \& Walker (1986) S & FES (1980), all employed, aged 18-59 & $\mathrm{C}$ & $\begin{array}{l}\text { Gorman polar form and } \\
\text { translog hours, } \mathrm{R}\end{array}$ & PL & & & .024 & & & -.287 \\
\hline & $\begin{array}{l}\text { Blundell, Ham \& Meghir } \\
(1987) £\end{array}$ & FES (1981), aged 16-60 & $\mathrm{T} / \mathrm{H}$ & $\begin{array}{l}\text { non-linear labor supply, } \\
\text { unemployment risk }\end{array}$ & own calc. & & {$[.04, .08]$} & & & & \\
\hline & $\begin{array}{l}\text { Blundell, Duncan \& Meghir } \\
\text { (1998) } \ £\end{array}$ & $\begin{array}{l}\text { FES (1978-1992), 20-50, young children } \\
\text { (lower bound if no child) }\end{array}$ & $\mathrm{C}$ & generalized LES, R & PL & {$[.13, .37] @$} & - & & & {$[-.19,0] @$} & \\
\hline & Blundell et al. (2000) \# & Family Resources Survey (1994-96) & $\mathrm{D}$ & $\mathrm{QU}+\mathrm{FC}, \mathrm{R}, \mathrm{W}$ & TAXBEN & {$[.11-.17]$} & & & & & \\
\hline
\end{tabular}

Note: see previous table. For Spain, several additional references are cited in García and Suárez (2003) which point to similar elasticities as in the basic model in this study. 
Table 3: Labor Supply Elasticities in Europe: Single Individuals

\begin{tabular}{|c|c|c|c|c|c|c|c|c|}
\hline \multirow{2}{*}{ Country } & \multirow{2}{*}{ Author } & \multirow{2}{*}{ Data selection } & \multirow{2}{*}{ Model } & \multirow{2}{*}{ Specification } & \multirow{2}{*}{ Tax-benefit } & \multicolumn{2}{|c|}{ wage elasticites } & \multirow{2}{*}{$\begin{array}{l}\text { income } \\
\text { elast. }\end{array}$} \\
\hline & & & & & & hours & particip. & \\
\hline Finland & Bargain \& Orsini (2006) \$ & IDS (1998), SW, SP & $\mathrm{D}$ & $\mathrm{QU}+\mathrm{FC}$ & EUROMOD & {$[.18, .34]$} & {$[.18, .33]$} & \\
\hline \multirow[t]{2}{*}{ France } & Bargain \& Orsini (2006) \$ & HBS (1994/5), aged 25-49, SW, SP & $\mathrm{D}$ & $\mathrm{QU}+\mathrm{FC}$ & EUROMOD & {$[.08, .14]$} & {$[.04, .07]$} & \\
\hline & Laroque \& Salanie (2001) & $\begin{array}{l}\text { LFS-Tax return matched dataset (1999), } \\
\text { women aged 25-49, no civil servants, } \\
\text { SW }\end{array}$ & $\mathrm{D}$ & $\begin{array}{l}\text { participation (and full/part-time) model, } \\
\text { simultaneous wage and labor supply estimation, } \\
\text { probability of unemployment, min. wage }\end{array}$ & own calc. & & $\{.36\}$ & \\
\hline \multirow[t]{10}{*}{ Germany } & Bargain \& Orsini (2006) \$ & SOEP (1998), SW, SP & $\mathrm{D}$ & $\mathrm{QU}+\mathrm{FC}$ & EUROMOD & {$[.09, .18]$} & {$[.08, .15]$} & \\
\hline & Steiner \& Wrohlich (2004) \$ & SOEP (2003), SW & $\mathrm{D}$ & $\mathrm{TU}+\mathrm{PTD}$ & STSM & {$[.20, .36]$} & {$[.05, .09]$} & \\
\hline & Haan \& Steiner (2005) \$ & SOEP (2002), SW & $\mathrm{D}$ & TU + PTD & STSM & {$[.02, .24]$} & {$[.01, .10]$} & \\
\hline & & SM & & & & {$[.08, .31]$} & {$[.04, .28]$} & \\
\hline & Clauss \& Schnabel (2006) \$ & SOEP (2004/5), aged 20-65, SW & $\mathrm{D}$ & $\mathrm{TU}+\mathrm{PTD}$ & STSM & .38 & .18 & \\
\hline & & SM & & & & .23 & .17 & \\
\hline & Bargain et al. (2009) & SOEP (2003), working age, SW & $\mathrm{D} / \mathrm{H}$ & QU + PTD; involuntary unemployment & STSM & {$[.06, .16]$} & {$[.04, .10]$} & \\
\hline & & SM & & & & {$[.10, .20]$} & {$[.05, .12]$} & \\
\hline & Fuest et al. (2008) & SOEP (2004), working age, SW & $\mathrm{D}$ & $\mathrm{TU}+\mathrm{PTD}$ & FiFoSiM & 0.28 & 0.13 & \\
\hline & & SM & & & & 0.28 & 0.17 & \\
\hline \multirow[t]{2}{*}{ Italy } & Aaberge et al. (2002) & $\begin{array}{l}\text { Survey on Household Income and } \\
\text { Wealth (1993), SW }\end{array}$ & A & GU & own calc. & .10 & .06 & \\
\hline & & SM & & & & .11 & .08 & \\
\hline \multirow[t]{2}{*}{ Netherlands } & Euwals \& Van Soest (1999) \# & $\begin{array}{l}\text { Dutch SOEP (1988), actual and desired } \\
\text { hours, SW }\end{array}$ & $\mathrm{D}$ & $\mathrm{TU}+\mathrm{FC}, \mathrm{R}$ & own calc. & {$[.03, .45]$} & & \\
\hline & & SM & & & & {$[.03, .18]$} & & \\
\hline \multirow[t]{2}{*}{ Sweden } & Andren (2003) & HINK (1997-98), SP & $\mathrm{D}$ & $\mathrm{QU}+\mathrm{FC}$; simulat. with $\mathrm{W}$ and $\mathrm{CC}$ & own calc. & {$[.55, .87]$} & .50 & -0.1 \\
\hline & Brink et al. (2007) & $\begin{array}{l}\text { Longitudinal Individual Data, IDS, } 1999 \text {, } \\
\text { SP }\end{array}$ & $\mathrm{D}$ & TU, R & FASIT & .51 & .35 & \\
\hline \multirow[t]{5}{*}{$U K$} & Walker $(1990) £$ & FES (1979-84), SP & $\mathrm{D}$ & participation model & benefits only & & .70 & \\
\hline & Ermisch \& Wright (1991) £ & General household survey (1973-82), SP & $\mathrm{D}$ & $\begin{array}{l}\text { participation model, demand-side } \\
\text { controls }\end{array}$ & simplified system & & 1.7 & \\
\hline & Jenkins $(1992) f$ & Lone parents survey (1989), SP & $\mathrm{D}+\mathrm{H}$ & $\begin{array}{l}\text { two positive hour choices, } \\
\text { unemployment risk, FC }\end{array}$ & benefits only & & 1.8 & \\
\hline & $\begin{array}{l}\text { Blundell, Duncan \& Meghir } \\
(1992) \rrbracket \mathcal{E}\end{array}$ & FES (1981-1986), SP & $\mathrm{C}$ & $\begin{array}{l}\text { marginal rate of substitution function, } \\
\text { endogenous wage and income }\end{array}$ & taxation only & & .34 & \\
\hline & Brewer et al. (2006) $f$ & FES (1995-2002), aged <60, SP & $\mathrm{D}$ & $\mathrm{QU}+\mathrm{FC}$, joint with $\mathrm{W}$ and $\mathrm{CC}, \mathrm{R}$ & TAXBEN & & 1.02 & \\
\hline
\end{tabular}

Authors: for references, see \ Blundell and MaCurdy (1999), \# Evers et al. (2008), £ Meghir and Phillips (2008), \& Orsini (2006)

Data \& Selection: Income Distribution Survey (IDS), Household Budget Survey (HBS), Socio Economic Panel (SOEP), Family Expenditure Survey (FES), Labor Force Survey (LFS); Selection: single women $(\mathrm{SW})$, single men (SM), single parents/mothers (SP)

Model: $\mathrm{C}=$ continuous LS (Hausman 1981 type); $\mathrm{T}=$ tobit model; $\mathrm{D}=$ discrete model (van Soest, 1995 type); $\mathrm{A}=$ estimation of joint distributions of wage and hours (sets of hour-wage opportunities vary across individuals); $\mathrm{H}=$ double hurdle model (labor supply and risk of unemployment).

Specification: for Hausman model, labor supply is either linear (LL), quadratic (QL) or semi-log (SL); in discrete-choice models, utility is either quadratic (QU), translog (TU) or generalized Stone-Geary (GU); random preferences (R); fixed costs (FC); welfare participation (W); childcare costs (CC)

Tax-benefit: Hausman model often accounts for piecewise-linear budget set (PL) or more generally convex set (C); nonconvexities are sometimes accounted for (NC); differentiability of the budget function can be used (D); with discrete choice models, complete tax-benefit systems are simulated and we indicate the name of the microsimulation model when it is known.

Elasticities: brackets indicate the range obtained in function of the specification at use, or the confidence interval when available. Particip. = participation elasticities, corresponding to the increase in employment rate in percentage points. 


\section{Table 4: Labor Supply Elasticities for the US}

\begin{tabular}{|c|c|c|c|c|c|c|c|c|c|}
\hline \multirow{2}{*}{ Authors } & \multirow{2}{*}{ Data selection } & \multirow{2}{*}{ Model } & \multirow{2}{*}{ Specification } & \multicolumn{2}{|c|}{ Female wage elast. } & \multicolumn{2}{|c|}{ Male wage elast. } & \multicolumn{2}{|c|}{ Income elast. } \\
\hline & & & & hours & particip. & hours & particip. & female & male \\
\hline $\operatorname{Cogan}(1981) £$ & $\begin{array}{l}\text { US National Longitudinal Study of } \\
\text { Mature Women 1967, married } \\
\text { women aged 30-35 }\end{array}$ & $\mathrm{C}$ & $\begin{array}{l}\text { SL; reservation hours to account for FC; no } \\
\text { tax-benefit }\end{array}$ & {$[.86,2.40]$} & & & & {$[.16, .66]$} & \\
\hline Hausman (1981) \# $\mathcal{E}$ & PSID 1975, married women & $\mathrm{C}$ & LL, PL (C and NC: FC) & {$[.90,1.00]$} & & & & {$[-.13,-.12]$} & \\
\hline Triest $(1990) £$ & $\begin{array}{l}\text { PSID 1983, married women, aged } \\
25-55\end{array}$ & $\mathrm{C}$ & LL; C and PL; taxes and benefits & {$[.03, .28]$} & & & & {$[-.15,-.19]$} & \\
\hline $\begin{array}{l}\text { MaCurdy, Green \& } \\
\text { Paarsch }(1990) £\end{array}$ & $\begin{array}{l}\text { PSID 1975: married men, aged 25- } \\
55\end{array}$ & $\mathrm{C}$ & $\begin{array}{l}\text { LL; PL and D (reconvexified) budget set; } \\
\text { taxes }\end{array}$ & & & {$[-.24, .03]$} & & -.01 & \\
\hline $\begin{array}{l}\text { Dickert, Houser and } \\
\text { Scholz (1995) } £\end{array}$ & SIPP 1990, single mothers, no assets & $\mathrm{D}$ & joint program and labor force participation & & .35 & & & & \\
\hline Pencavel $(1998) £$ & CPS 1975-94, women aged 25-60 & $\mathrm{C}$ & Log-L; no tax-benefit & & {$[.77, .1 .80]$} & & & & \\
\hline Hoynes (1996) & $\begin{array}{l}\text { SIPP panel, 1984, married men and } \\
\text { women with children }\end{array}$ & $\mathrm{D}$ & $\begin{array}{l}\text { Stone-Geary; stigma from AFDC; tax- } \\
\text { benefit system; FC }\end{array}$ & & & & & -.46 & -.12 \\
\hline $\begin{array}{l}\text { Keane and Moffitt } \\
(1998) £\end{array}$ & 1994 SIPP, single mothers, no assets & $\mathrm{D}$ & $\begin{array}{l}\text { joint labor supply and welfare program } \\
\text { participation; benefits but no tax }\end{array}$ & & .96 & & & & \\
\hline Pencavel $(2002) \AA$ & CPS 1999, married and single men & $\mathrm{C}$ & LL; no tax-benefit & & & {$[.12, .25]$} & & & \\
\hline Devereux (2003) \# & Census and PSID, all men & $\mathrm{C}$ & Log-L, no tax-benefit & & & {$[-.022, .017]$} & {$[-.061, .001]$} & & \\
\hline Devereux (2004) \# & $\begin{array}{l}\text { PUMS 1980,1990, married couples } \\
\text { (participating men) }\end{array}$ & $\mathrm{C}$ & Log-L, no tax-benefit & {$[.17,38]$} & & {$[.00, .07]$} & & & \\
\hline $\begin{array}{l}\text { Eissa \& Hoynes (2004) } \\
\text { \# }\end{array}$ & $\begin{array}{l}\text { CPS } 1985 \text { to } 1997 \text {, less educated } \\
\text { married couples with children }\end{array}$ & $\mathrm{D}$ & Participation Probit, joint estimation & & 0.27 & & .03 & -.039 & -.007 \\
\hline \multirow[t]{3}{*}{ Blau \& Kahn (2007) \# } & $\begin{array}{l}\text { CPS } 1980 \text {, married men and women } \\
\text { age } 25-54\end{array}$ & $\mathrm{C}$ & $\log -\mathrm{L}$ & {$[.77,88]$} & & {$[.01,07]$} & & .004 & .001 \\
\hline & CPS 1990 & $\mathrm{C}$ & $\log -\mathrm{L}$ & {$[.58, .64]$} & & {$[.10, .14]$} & & .002 & .002 \\
\hline & CPS 2000 & $\mathrm{C}$ & $\log -\mathrm{L}$ & {$[.36,41]$} & & {$[.04, .10]$} & & .001 & .002 \\
\hline Heim (2009) & PSID 2001, couples & & $\begin{array}{l}\text { quadratic utility with continuous labor } \\
\text { supply, J, FC, R }\end{array}$ & {$[.24,33]$} & {$[.07,18]$} & {$[.04,07]$} & {$[.00, .003]$} & {$[-.007,-.006]$} & $\begin{array}{l}{[-.0007,-} \\
.0004\}\end{array}$ \\
\hline Bishop et al. (2009) & CPS, 1979-2003, sing. women & & SL, participation, some account for tax & $\begin{array}{l}.14(1979) \text { to }- \\
.03(2003)\end{array}$ & $\begin{array}{l}.28(1979) \text { to } \\
.22(2003)\end{array}$ & & & $\begin{array}{l}-.014(1979) \text { to }- \\
.019(2003)\end{array}$ & \\
\hline Heim (2007) & CPS, 1979-2003, married women & & SL, participation, some account for tax & $\begin{array}{l}.36(1979) \text { to } \\
.14(2003)\end{array}$ & $\begin{array}{l}.66(1979) \text { to } \\
.03(2003)\end{array}$ & & & $\begin{array}{l}-.05(1979) \text { to }- \\
.015(2003)\end{array}$ & \\
\hline
\end{tabular}

Authors: for references, see $₫$ Blundell and MaCurdy (1999), \# Evers et al. (2008), £ Meghir and Phillips (2008)

Data: Current Population Survey (CPS), Panel Study on Income Dynamics (PSID), Public Use Microdata Sample (PUMS), Survey of Income and Program Participation (SIPP)

Model: $\mathrm{C}=$ continuous labor supply (Hausman 1981 type); $\mathrm{D}=$ discrete-choice model (often a simple participation probit)

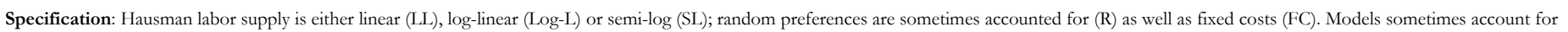
piecewise-linear budget set (PL) or more generally convex set (C) or nonconvexities (NC), and differentiable budget constraint (D).

Elasticities: brackets indicate ranges of values over different specifications, or reported confidence intervals. Participation elasticities ("particip"): increase in employ. rate in \% points. 
Table 5: Descriptive Statistics (Selected Samples)

\begin{tabular}{|c|c|c|c|c|c|c|c|c|c|c|c|c|c|c|c|c|c|c|c|c|c|c|c|c|c|}
\hline Country & $\mathrm{AT}$ & $\mathrm{BE}$ & BE & DK & FI & FR & FR & GE & GE & GR & IE & IE & IT & NL & PT & SP & SP & UK & UK & SW & SW & EE & $\mathrm{HU}$ & PL & US \\
\hline Year & 98 & 98 & 01 & 98 & 98 & 98 & 01 & 98 & 01 & 98 & 98 & 01 & 98 & 01 & 01 & 98 & 01 & 98 & 01 & 98 & 01 & 05 & 05 & 05 & 05 \\
\hline Data & ECHP & PS & SB & ECHP & IDS & $\mathrm{Hl}$ & BS & SO & EP & HBS & & IS & SHIW & SOEP & ECHP & $\mathrm{EC}$ & CHP & F & ES & II & DS & HBS & HBS & HBS & CPS \\
\hline \multicolumn{26}{|l|}{ Couples } \\
\hline \multicolumn{26}{|l|}{ Women } \\
\hline Age & 39 & 39 & 40 & 38 & 40 & 38 & 39 & 39 & 39 & 38 & 40 & 42 & 39 & 38 & 37 & 39 & 39 & 37 & 38 & 39 & 41 & 43 & 38 & 39 & 39 \\
\hline Tertiary educ. & .26 & .09 & .10 & .38 & .42 & .20 & .26 & .30 & .33 & .24 & .12 & .21 & .09 & .27 & .12 & .17 & .26 & .29 & .35 & .31 & .36 & .40 & .19 & .19 & .33 \\
\hline Hourly wage & 9.9 & 11.4 & 12.8 & 13.3 & 10.4 & 10.2 & 10.1 & 11.4 & 11.8 & 3.8 & 7.6 & 10.8 & 7.4 & 11.4 & 4.3 & 5.6 & 6.4 & 8.6 & 11.3 & 10.3 & 11.6 & 2.0 & 2.1 & 2.3 & 13.8 \\
\hline Weekly hours & 17.2 & 24.1 & 24.5 & 28.6 & 31.7 & 23.2 & 23.9 & 19.7 & 20.8 & 13.3 & 11.3 & 17.7 & 15.1 & 18.6 & 27.5 & 12.2 & 15.0 & 21.3 & 22.6 & 28.3 & 30.6 & 33.4 & 28.8 & 23.2 & 26.9 \\
\hline Weekly hours* & 29.9 & 32.8 & 32.4 & 34.4 & 37.4 & 33.9 & 33.0 & 29.8 & 29.6 & 36.6 & 29.4 & 29.5 & 33.0 & 25.4 & 38.0 & 34.5 & 34.9 & 30.3 & 30.3 & 32.3 & 33.0 & 38.9 & 38.9 & 37.9 & 38.1 \\
\hline Particip. rate & .57 & .73 & .75 & .83 & .85 & .68 & .73 & .66 & .70 & .36 & .38 & .60 & .46 & .73 & .72 & .35 & .43 & .70 & .75 & .88 & .93 & .86 & .74 & .61 & .71 \\
\hline \multicolumn{26}{|l|}{ Men } \\
\hline Age & 42 & 41 & 42 & 40 & 42 & 40 & 41 & 41 & 41 & 42 & 42 & 44 & 42 & 41 & 40 & 41 & 41 & 39 & 40 & 42 & 43 & 45 & 41 & 41 & 41 \\
\hline Tertiary educ. & .26 & .12 & .13 & .37 & .38 & .19 & .25 & .38 & .39 & .26 & .18 & .23 & .10 & .34 & .09 & .23 & .27 & .28 & .31 & .30 & .32 & .23 & .17 & .14 & .32 \\
\hline Hourly wage & 14.9 & 14.3 & 15.6 & 16.4 & 14.0 & 12.6 & 12.9 & 15.3 & 16.2 & 5.4 & 10.9 & 14.9 & 9.2 & 16.3 & 5.5 & 7.3 & 8.2 & 12.8 & 16.6 & 13.5 & 15.8 & 2.7 & 2.8 & 3.2 & 20.3 \\
\hline Weekly hours & 40.8 & 39.2 & 39.7 & 37.5 & 37.8 & 38.5 & 38.3 & 35.3 & 35.5 & 38.5 & 32.4 & 37.0 & 36.3 & 39.2 & 40.8 & 37.6 & 39.7 & 37.8 & 37.9 & 35.6 & 36.8 & 36.0 & 37.7 & 33.3 & 41.1 \\
\hline Weekly hours* & 42.1 & 42.0 & 41.7 & 40.9 & 41.5 & 41.4 & 40.7 & 38.1 & 38.2 & 42.6 & 41.6 & 40.4 & 39.9 & 40.7 & 42.2 & 43.1 & 42.6 & 44.3 & 42.8 & 38.5 & 38.3 & 40.9 & 42.1 & 38.7 & 44.4 \\
\hline Particip. rate & .97 & .93 & .95 & .92 & .91 & .93 & .94 & .92 & .93 & .90 & .78 & .91 & .91 & .96 & .97 & .87 & .93 & .85 & .89 & .93 & .96 & .88 & .89 & .86 & .93 \\
\hline \# children & 1.5 & 1.5 & 1.5 & 1.2 & 1.3 & 1.5 & 1.4 & 1.3 & 1.2 & 1.5 & 2.4 & 2.2 & 1.7 & 1.3 & 1.4 & 1.7 & 1.5 & 1.3 & 1.3 & 1.1 & 1.3 & 1.5 & 1.5 & 1.7 & 1.5 \\
\hline 1 (children $0-2$ ) & .13 & .14 & .14 & .18 & .15 & .19 & .18 & .13 & .11 & .10 & .23 & .17 & .14 & .18 & .17 & .14 & .16 & .20 & .17 & .18 & .15 & .03 & .15 & .15 & .19 \\
\hline \multicolumn{26}{|l|}{ Single women } \\
\hline Age & 40 & 41 & 42 & 38 & 42 & 39 & 40 & 38 & 38 & 43 & 40 & 41 & 42 & 39 & 44 & 42 & 42 & 38 & 39 & 37 & 40 & 45 & 43 & 42 & 40 \\
\hline Tertiary educ. & .32 & .10 & .11 & .35 & .38 & .24 & .31 & .33 & .39 & .24 & .13 & .19 & .12 & .33 & .15 & .31 & .35 & .25 & .32 & .29 & .34 & .35 & .22 & .23 & .27 \\
\hline Hourly wage & 11.3 & 11.6 & 13.3 & 13.2 & 10.9 & 10.1 & 10.6 & 12.4 & 12.3 & 3.6 & 7.4 & 9.7 & 8.0 & 11.6 & 5.0 & 6.3 & 7.2 & 8.9 & 11.8 & 10.6 & 11.8 & 2.0 & 2.6 & 2.5 & 13.4 \\
\hline Weekly hours & 29.3 & 25.2 & 27.2 & 27.5 & 31.0 & 29.7 & 28.8 & 25.8 & 26.9 & 21.9 & 17.8 & 22.7 & 26.8 & 25.2 & 29.7 & 26.7 & 28.0 & 20.3 & 22.3 & 25.8 & 29.7 & 33.6 & 33.7 & 26.2 & 32.7 \\
\hline Weekly hours* & 34.4 & 35.3 & 34.6 & 34.5 & 37.9 & 35.1 & 34.9 & 33.1 & 33.2 & 39.3 & 34.9 & 31.2 & 35.2 & 31.8 & 37.7 & 37.6 & 36.2 & 33.1 & 33.8 & 32.1 & 33.0 & 39.3 & 39.4 & 37.1 & 40.4 \\
\hline Particip. rate & 0.85 & 0.72 & 0.79 & 0.80 & 0.82 & 0.85 & 0.83 & 0.78 & 0.81 & 0.56 & 0.51 & 0.73 & 0.76 & 0.79 & 0.79 & 0.71 & 0.78 & 0.61 & 0.66 & 0.80 & 0.90 & 0.86 & 0.86 & 0.71 & 0.81 \\
\hline \# children & 0.8 & 0.7 & 0.8 & 0.6 & 0.6 & 0.7 & 0.7 & 0.7 & 0.6 & 0.8 & 1.4 & 1.3 & 0.8 & 0.5 & 1.0 & 1.0 & 0.8 & 1.1 & 1.0 & 0.4 & 0.7 & 1.0 & 1.0 & 1.2 & 1.0 \\
\hline \multicolumn{26}{|l|}{ Single men } \\
\hline Age & 38 & 40 & 43 & 37 & 39 & 38 & 39 & 38 & 38 & 38 & 41 & 41 & 39 & 37 & 40 & 40 & 40 & 38 & 40 & 35 & 38 & 40 & 41 & 41 & 40 \\
\hline Tertiary educ. & .26 & .09 & .07 & .34 & .27 & .22 & .31 & .36 & .34 & .34 & .20 & .17 & .16 & .35 & .06 & .25 & .29 & .31 & .35 & .21 & .27 & .14 & .17 & .14 & .27 \\
\hline Hourly wage & 13.6 & 12.3 & 14.0 & 15.0 & 11.7 & 11.3 & 11.2 & 14.3 & 14.5 & 4.7 & 8.7 & 10.4 & 8.6 & 13.0 & 4.5 & 6.6 & 7.2 & 11.0 & 13.9 & 11.3 & 13.4 & 1.7 & 2.5 & 2.4 & 15.9 \\
\hline Weekly hours & 37.0 & 35.0 & 34.7 & 31.9 & 30.7 & 33.7 & 33.2 & 31.7 & 32.6 & 31.7 & 25.3 & 27.4 & 28.5 & 35.0 & 33.2 & 28.0 & 33.2 & 29.3 & 32.3 & 26.6 & 30.9 & 30.7 & 33.0 & 23.1 & 36.2 \\
\hline Weekly hours* & 39.7 & 40.6 & 41.3 & 38.2 & 40.5 & 39.1 & 37.8 & 36.8 & 36.5 & 41.3 & 41.0 & 37.9 & 37.8 & 37.8 & 42.1 & 40.4 & 40.6 & 42.2 & 40.4 & 34.5 & 34.9 & 40.4 & 41.0 & 36.8 & 42.8 \\
\hline Particip. rate & 0.93 & 0.86 & 0.84 & 0.83 & 0.76 & 0.86 & 0.88 & 0.86 & 0.89 & 0.77 & 0.62 & 0.72 & 0.75 & 0.93 & 0.79 & 0.69 & 0.82 & 0.70 & 0.80 & 0.77 & 0.88 & 0.76 & 0.80 & 0.63 & 0.84 \\
\hline \# children & 0.1 & 0.1 & 0.1 & 0.1 & 0.1 & 0.1 & 0.2 & 0.2 & 0.2 & 0.1 & 0.2 & 0.2 & 0.2 & 0.1 & 0.3 & 0.3 & 0.2 & 0.1 & 0.2 & 0.0 & 0.1 & 0.1 & 0.2 & 0.3 & 0.2 \\
\hline Sample size & 1,323 & 1,933 & 1,480 & 1,912 & 4,813 & 6,377 & 5,764 & 4,490 & 4,164 & 1,634 & 1,898 & 1,502 & 3,014 & 2,569 & 1,812 & 2,857 & 2,344 & 3,197 & 3,070 & 9,861 & 7,499 & 1,547 & 2,683 & 14,695 & 38,119 \\
\hline Belgian Househ & $2 x_{p}$ & & $S_{u}$ & 0 & 6 & & & & & & & & & & & & & & & & & & & & \\
\hline
\end{tabular}


Table 6: Distributions of Weekly Worked Hours (Selected Samples)

\begin{tabular}{|c|c|c|c|c|c|c|c|c|c|c|c|c|c|}
\hline & AT & $\mathrm{BE}$ & $\mathrm{BE}$ & DK & FI & FR & FR & GE & GE & GR & IE & IE & IT \\
\hline & 98 & 98 & 01 & 98 & 98 & 98 & 01 & 98 & 01 & 98 & 98 & 01 & 98 \\
\hline \multicolumn{14}{|l|}{ All males } \\
\hline $0-4$ & 0.04 & 0.10 & 0.08 & 0.11 & 0.15 & 0.09 & 0.08 & 0.10 & 0.10 & 0.11 & 0.25 & 0.11 & 0.12 \\
\hline $5-14$ & 0.01 & 0.00 & 0.00 & 0.01 & 0.01 & 0.01 & 0.01 & 0.02 & 0.03 & 0.00 & 0.01 & 0.01 & 0.01 \\
\hline $15-24$ & 0.02 & 0.03 & 0.04 & 0.01 & 0.02 & 0.03 & 0.03 & 0.04 & 0.03 & 0.03 & 0.05 & 0.06 & 0.04 \\
\hline $25-34$ & 0.02 & 0.04 & 0.05 & 0.03 & 0.05 & 0.04 & 0.21 & 0.12 & 0.11 & 0.06 & 0.07 & 0.06 & 0.03 \\
\hline $35-44$ & 0.72 & 0.66 & 0.65 & 0.69 & 0.66 & 0.67 & 0.51 & 0.66 & 0.70 & 0.59 & 0.43 & 0.59 & 0.66 \\
\hline $45-54$ & 0.12 & 0.11 & 0.13 & 0.09 & 0.07 & 0.12 & 0.12 & 0.03 & 0.02 & 0.11 & 0.12 & 0.13 & 0.10 \\
\hline $55+$ & 0.06 & 0.05 & 0.05 & 0.06 & 0.04 & 0.05 & 0.05 & 0.03 & 0.02 & 0.10 & 0.08 & 0.05 & 0.04 \\
\hline \multicolumn{14}{|l|}{ All females } \\
\hline $0-4$ & 0.33 & 0.29 & 0.23 & 0.20 & 0.18 & 0.30 & 0.27 & 0.33 & 0.28 & 0.61 & 0.59 & 0.35 & 0.51 \\
\hline $5-14$ & 0.05 & 0.04 & 0.03 & 0.02 & 0.01 & 0.03 & 0.03 & 0.07 & 0.08 & 0.00 & 0.04 & 0.04 & 0.01 \\
\hline $15-24$ & 0.17 & 0.25 & 0.28 & 0.07 & 0.04 & 0.10 & 0.10 & 0.12 & 0.13 & 0.04 & 0.09 & 0.20 & 0.10 \\
\hline $25-34$ & 0.10 & 0.09 & 0.12 & 0.16 & 0.10 & 0.11 & 0.23 & 0.12 & 0.12 & 0.06 & 0.06 & 0.10 & 0.04 \\
\hline $35-44$ & 0.33 & 0.31 & 0.31 & 0.51 & 0.64 & 0.42 & 0.32 & 0.35 & 0.37 & 0.25 & 0.19 & 0.27 & 0.31 \\
\hline $45-54$ & 0.02 & 0.02 & 0.02 & 0.03 & 0.02 & 0.03 & 0.04 & 0.01 & 0.01 & 0.03 & 0.02 & 0.02 & 0.02 \\
\hline \multirow[t]{3}{*}{$55+$} & 0.00 & 0.01 & 0.01 & 0.01 & 0.01 & 0.01 & 0.01 & 0.01 & 0.02 & 0.01 & 0.01 & 0.01 & 0.01 \\
\hline & NL & PT & SP & SP & UK & UK & SW & SW & $\mathrm{EE}$ & $\mathrm{HU}$ & PL & US & Mean \\
\hline & 01 & 01 & 98 & 01 & 98 & 01 & 98 & 01 & 05 & 05 & 05 & 05 & \\
\hline \multicolumn{14}{|l|}{ All males } \\
\hline $0-4$ & 0.05 & 0.06 & 0.15 & 0.09 & 0.19 & 0.13 & 0.15 & 0.08 & 0.12 & 0.12 & 0.17 & 0.10 & 0.11 \\
\hline $5-14$ & 0.01 & 0.00 & 0.00 & 0.02 & 0.00 & 0.01 & 0.05 & 0.05 & 0.00 & 0.01 & 0.00 & 0.00 & 0.01 \\
\hline $15-24$ & 0.03 & 0.02 & 0.02 & 0.02 & 0.01 & 0.02 & 0.06 & 0.05 & 0.02 & 0.02 & 0.05 & 0.01 & 0.03 \\
\hline $25-34$ & 0.08 & 0.10 & 0.07 & 0.07 & 0.05 & 0.08 & 0.08 & 0.09 & 0.02 & 0.02 & 0.00 & 0.02 & 0.06 \\
\hline $35-44$ & 0.67 & 0.62 & 0.55 & 0.61 & 0.48 & 0.53 & 0.56 & 0.65 & 0.73 & 0.67 & 0.78 & 0.56 & 0.62 \\
\hline $45-54$ & 0.11 & 0.13 & 0.13 & 0.13 & 0.18 & 0.16 & 0.06 & 0.05 & 0.07 & 0.11 & 0.00 & 0.20 & 0.10 \\
\hline $55+$ & 0.05 & 0.07 & 0.07 & 0.07 & 0.09 & 0.07 & 0.04 & 0.04 & 0.04 & 0.06 & 0.00 & 0.10 & 0.06 \\
\hline \multicolumn{14}{|l|}{ All females } \\
\hline $0-4$ & 0.27 & 0.23 & 0.60 & 0.55 & 0.32 & 0.27 & 0.16 & 0.10 & 0.14 & 0.22 & 0.36 & 0.26 & 0.32 \\
\hline $5-14$ & 0.09 & 0.02 & 0.03 & 0.03 & 0.08 & 0.06 & 0.07 & 0.07 & 0.01 & 0.01 & 0.00 & 0.01 & 0.04 \\
\hline $15-24$ & 0.22 & 0.05 & 0.05 & 0.05 & 0.13 & 0.14 & 0.11 & 0.10 & 0.05 & 0.05 & 0.07 & 0.05 & 0.11 \\
\hline $25-34$ & 0.19 & 0.19 & 0.08 & 0.10 & 0.13 & 0.17 & 0.23 & 0.20 & 0.04 & 0.05 & 0.00 & 0.07 & 0.11 \\
\hline $35-44$ & 0.20 & 0.44 & 0.21 & 0.23 & 0.29 & 0.32 & 0.39 & 0.47 & 0.71 & 0.60 & 0.57 & 0.49 & 0.38 \\
\hline $45-54$ & 0.02 & 0.04 & 0.03 & 0.03 & 0.04 & 0.03 & 0.03 & 0.03 & 0.03 & 0.05 & 0.00 & 0.09 & 0.03 \\
\hline $55+$ & 0.01 & 0.04 & 0.01 & 0.01 & 0.01 & 0.01 & 0.02 & 0.02 & 0.02 & 0.03 & 0.00 & 0.03 & 0.01 \\
\hline
\end{tabular}


Table 7: Goodness of Fit: Hour Mean and Distributions

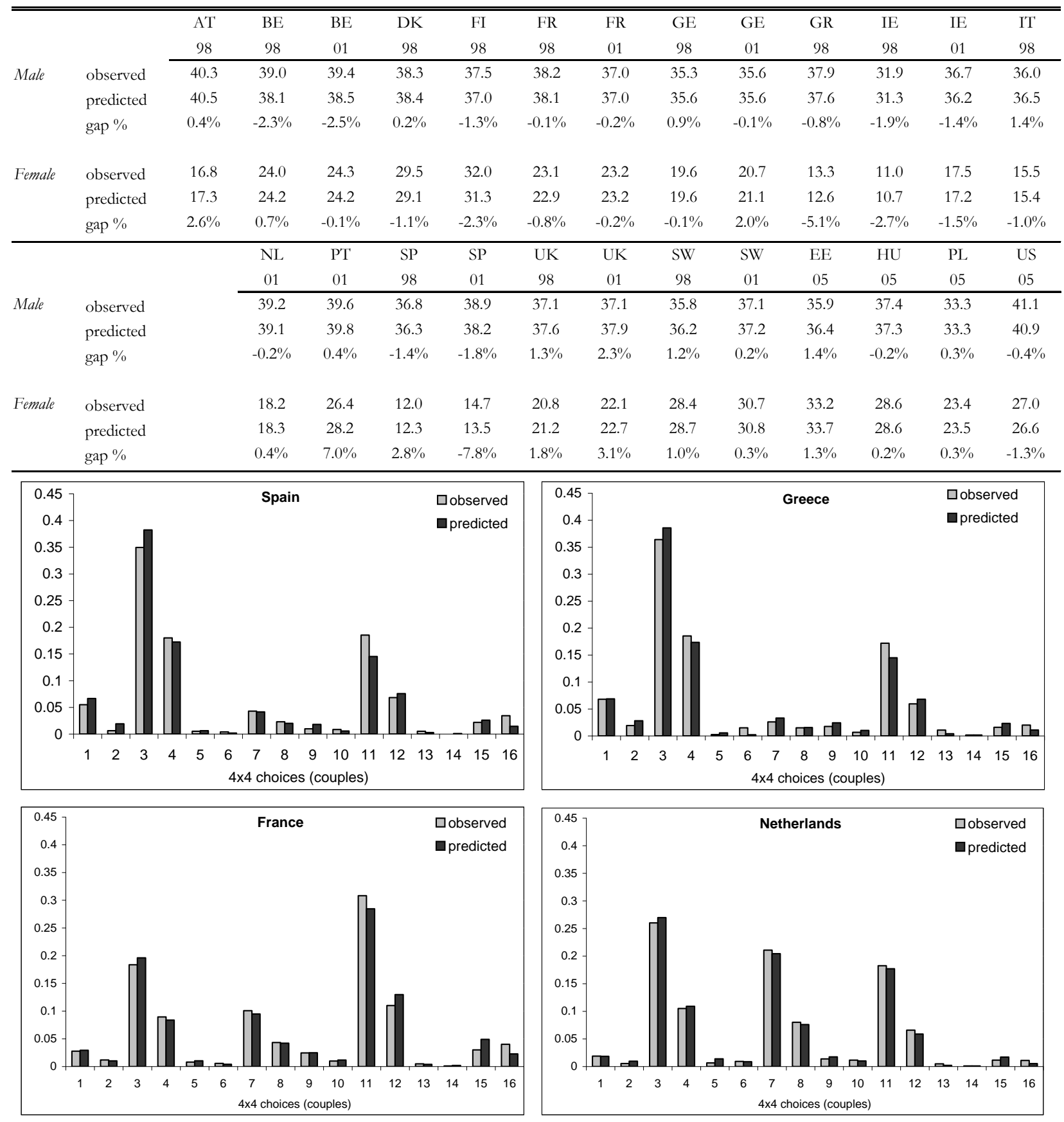


Table 8: Labor Supply Elasticities: Couples

\begin{tabular}{|c|c|c|c|c|c|c|c|c|c|c|c|c|c|}
\hline & AT & $\mathrm{BE}$ & $\mathrm{BE}$ & $\mathrm{DK}$ & FI & FR & FR & GE & GE & GR & IE & IE & IT \\
\hline & 98 & 98 & 01 & 98 & 98 & 98 & 01 & 98 & 01 & 98 & 98 & 01 & 98 \\
\hline \multicolumn{14}{|l|}{ Women in couples } \\
\hline \multicolumn{14}{|l|}{ Own-wage elasticity } \\
\hline \multirow[t]{2}{*}{ Hours } & .34 & .28 & .31 & .30 & .13 & .23 & .13 & .31 & .31 & .62 & .47 & .32 & .33 \\
\hline & $(.04)$ & (.03) & $(.05)$ & $(.03)$ & $(.01)$ & $(.02)$ & $(.01)$ & $(.03)$ & $(.01)$ & $(.06)$ & $(.05)$ & $(.04)$ & $(.03)$ \\
\hline quintile 1 & .34 & .25 & .34 & .28 & .12 & .21 & .09 & .35 & .31 & .58 & .43 & .39 & .30 \\
\hline quintile 2 & .32 & .23 & .27 & .31 & .11 & .20 & .09 & .30 & .30 & .58 & .38 & .33 & .29 \\
\hline quintile 3 & .32 & .25 & .29 & .26 & .12 & .21 & .10 & .30 & .31 & .59 & .40 & .28 & .29 \\
\hline quintile 4 & .33 & .29 & .31 & .27 & .14 & .24 & .14 & .30 & .31 & .61 & .42 & .30 & .32 \\
\hline quintile 5 & .37 & .41 & .36 & .36 & .16 & .27 & .21 & .30 & .34 & .68 & .73 & .30 & .40 \\
\hline with children & .35 & .28 & .30 & .31 & .14 & .24 & .13 & .31 & .34 & .63 & .56 & .35 & .31 \\
\hline no children & .31 & .29 & .34 & .28 & .12 & .20 & .12 & .30 & .28 & .53 & .23 & .21 & .38 \\
\hline Hours: participants only* & .05 & .05 & .05 & .06 & .01 & .03 & .02 & .06 & .08 & .03 & .08 & .05 & .05 \\
\hline \multirow[t]{2}{*}{ Participation** } & .27 & .22 & .23 & .25 & .12 & .19 & .10 & .24 & .22 & .57 & .42 & .27 & .28 \\
\hline & (.03) & $(.02)$ & (.03) & $(.02)$ & $(.01)$ & $(.01)$ & $(.01)$ & $(.02)$ & $(.01)$ & $(.05)$ & $(.04)$ & $(.03)$ & $(.03)$ \\
\hline \multicolumn{14}{|l|}{ Cross-wage elasticity } \\
\hline \multirow[t]{2}{*}{ Hours } & -.13 & -.07 & -.05 & -.14 & -.07 & -.11 & -.07 & -.19 & -.17 & -.09 & -.22 & -.14 & .04 \\
\hline & $(.04)$ & (.03) & $(.04)$ & $(.03)$ & $(.02)$ & $(.01)$ & $(.02)$ & $(.02)$ & (.03) & $(.05)$ & $(.04)$ & (.04) & $(.03)$ \\
\hline \multirow[t]{2}{*}{ Participation** } & -.10 & -.05 & -.04 & -.11 & -.05 & -.08 & -.05 & -.13 & -.11 & -.09 & -.17 & -.10 & .03 \\
\hline & (.03) & $(.02)$ & (.03) & $(.02)$ & $(.01)$ & $(.01)$ & $(.01)$ & $(.02)$ & $(.02)$ & $(.04)$ & (.03) & (.03) & (.03) \\
\hline \multicolumn{14}{|l|}{ Income elasticity } \\
\hline \multirow[t]{2}{*}{ Hours } & -.001 & -.002 & -.002 & -.004 & .001 & -.003 & -.002 & -.006 & -.006 & -.004 & -.008 & .007 & .001 \\
\hline & $(.000)$ & $(.001)$ & $(.001)$ & $(.000)$ & $(.000)$ & $(.000)$ & $(.001)$ & $(.001)$ & $(.001)$ & $(.002)$ & $(.001)$ & $(.002)$ & $(.004)$ \\
\hline \multirow[t]{2}{*}{ Participation** } & -.001 & -.002 & -.001 & -.003 & .001 & -.002 & -.002 & -.004 & -.004 & -.004 & -.007 & .007 & .001 \\
\hline & $(.000)$ & $(.001)$ & $(.001)$ & $(.000)$ & $(.000)$ & $(.000)$ & $(.000)$ & $(.001)$ & $(.001)$ & $(.002)$ & $(.001)$ & $(.002)$ & $(.004)$ \\
\hline \multicolumn{14}{|l|}{ Men in couples } \\
\hline \multicolumn{14}{|l|}{ Own-wage elasticity } \\
\hline \multirow[t]{2}{*}{ Hours } & .07 & .13 & .12 & .15 & .10 & .09 & .06 & .13 & .14 & .11 & .26 & .15 & .04 \\
\hline & $(.02)$ & $(.01)$ & $(.02)$ & $(.02)$ & $(.01)$ & $(.01)$ & $(.01)$ & $(.01)$ & $(.01)$ & $(.02)$ & $(.02)$ & $(.02)$ & $(.01)$ \\
\hline quintile 1 & .08 & .15 & .16 & .20 & .12 & .10 & .05 & .19 & .18 & .12 & .41 & .21 & .03 \\
\hline quintile 2 & .08 & .11 & .12 & .16 & .10 & .09 & .05 & .12 & .13 & .11 & .26 & .16 & .03 \\
\hline quintile 3 & .07 & .10 & .11 & .11 & .09 & .09 & .05 & .13 & .13 & .11 & .21 & .14 & .03 \\
\hline quintile 4 & .07 & .12 & .10 & .11 & .08 & .08 & .06 & .12 & .12 & .11 & .18 & .12 & .04 \\
\hline quintile 5 & .07 & .16 & .11 & .18 & .10 & .08 & .09 & .10 & .12 & .13 & .26 & .14 & .06 \\
\hline Hours: participants only* & .02 & .02 & .02 & .02 & .00 & .02 & .02 & .03 & .03 & .01 & .00 & .03 & -.01 \\
\hline \multirow[t]{2}{*}{ Participation** } & .05 & .10 & .09 & .13 & .10 & .07 & .04 & .10 & .11 & .10 & .27 & .12 & .05 \\
\hline & $(.01)$ & $(.01)$ & $(.01)$ & $(.01)$ & $(.01)$ & $(.01)$ & $(.00)$ & $(.01)$ & $(.01)$ & $(.01)$ & $(.01)$ & $(.02)$ & $(.01)$ \\
\hline \multicolumn{14}{|l|}{ Cross-wage elasticity } \\
\hline \multirow[t]{2}{*}{ Hours } & -.01 & -.02 & -.01 & -.05 & -.03 & -.01 & -.01 & -.05 & -.06 & -.04 & -.07 & -.02 & -.04 \\
\hline & $(.01)$ & $(.01)$ & $(.01)$ & $(.01)$ & $(.01)$ & $(.00)$ & $(.00)$ & $(.01)$ & $(.01)$ & $(.01)$ & $(.01)$ & $(.01)$ & $(.01)$ \\
\hline \multirow[t]{2}{*}{ Participation** } & .00 & -.01 & .00 & -.03 & -.02 & .00 & .00 & -.03 & -.04 & -.03 & -.05 & -.01 & -.03 \\
\hline & $(.00)$ & $(.01)$ & $(.00)$ & $(.01)$ & $(.01)$ & $(.00)$ & $(.00)$ & $(.00)$ & $(.01)$ & $(.01)$ & $(.01)$ & $(.01)$ & $(.00)$ \\
\hline Income elasticity & & & & & & & & & & & & & \\
\hline Hours & .000 & -.002 & -.002 & -.003 & .001 & .000 & .000 & -.003 & -.004 & -.005 & -.010 & -.004 & -.017 \\
\hline & $(.000)$ & $(.000)$ & $(.001)$ & $(.000)$ & $(.000)$ & $(.000)$ & $(.000)$ & $(.000)$ & $(.000)$ & $(.001)$ & $(.001)$ & $(.001)$ & $(.002)$ \\
\hline Participation $* *$ & .000 & -.001 & -.001 & -.002 & .001 & .001 & .000 & -.002 & -.002 & -.003 & -.008 & -.002 & -.013 \\
\hline & $(.000)$ & $(.000)$ & $(.000)$ & $(.000)$ & $(.000)$ & $(.000)$ & $(.000)$ & $(.000)$ & $(.000)$ & $(.001)$ & $(.001)$ & $(.000)$ & $(.002)$ \\
\hline
\end{tabular}

Note: elasticities are computed numerically by simulation of responses to a $1 \%$ uniform increase in wage rates or unearned income. Bootstrapped standard errors in brackets.

* pure intensive margin, ** pure extensive margin 
Table 9: Labor Supply Elasticities: Couples (cont.)

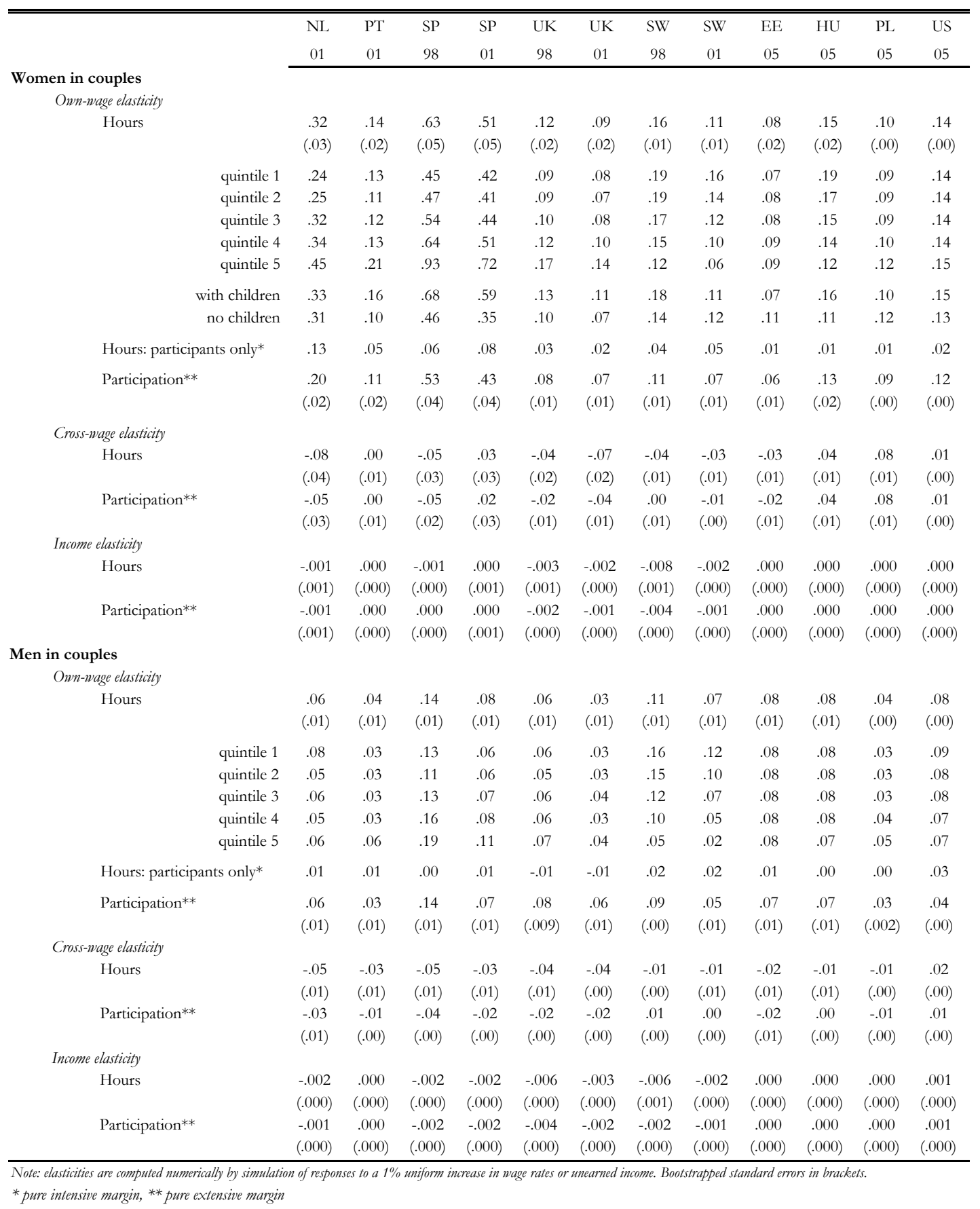


Table 10: Labor Supply Elasticities: Single Women

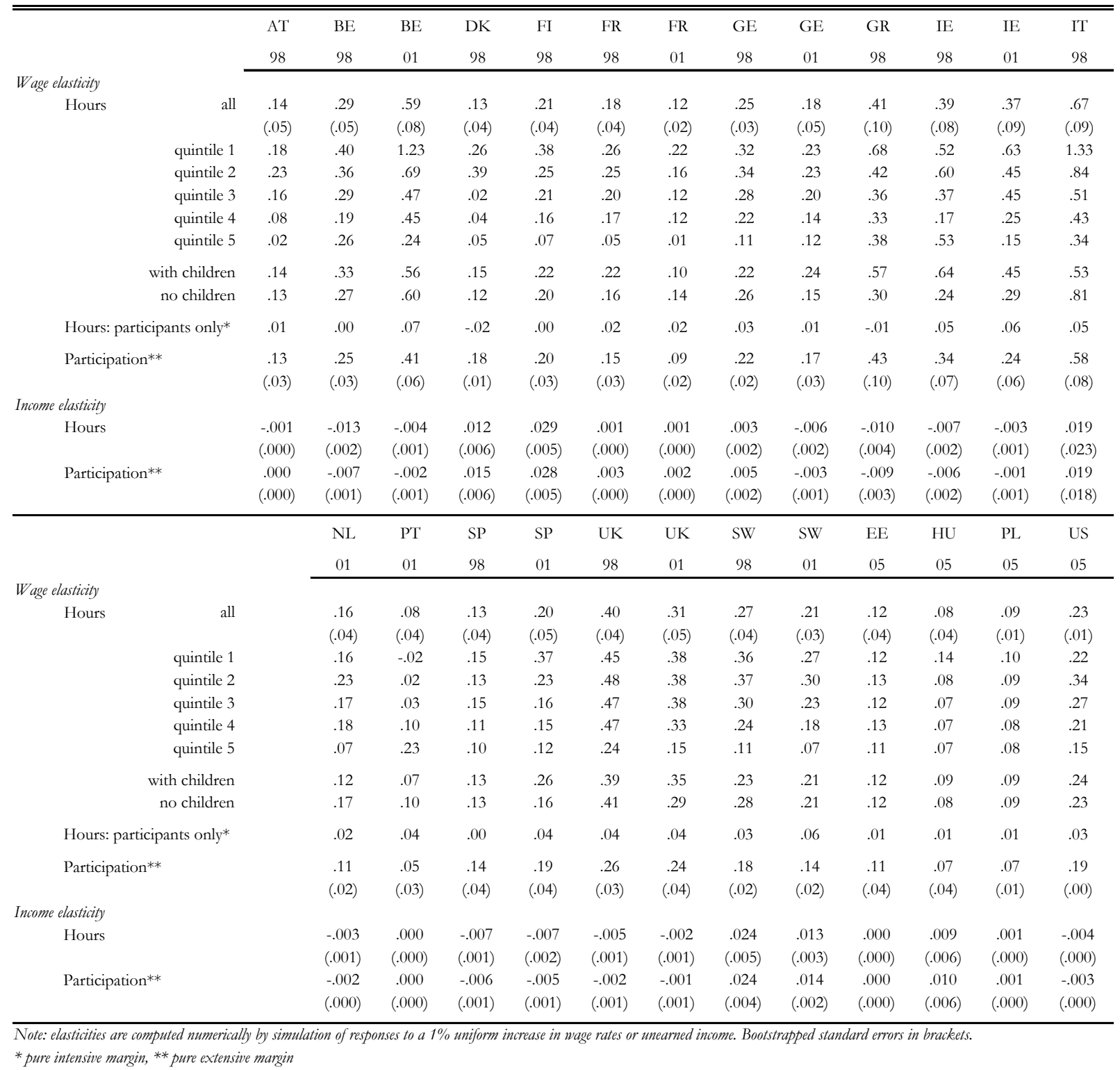


Table 11: Labor Supply Elasticities: Single Men

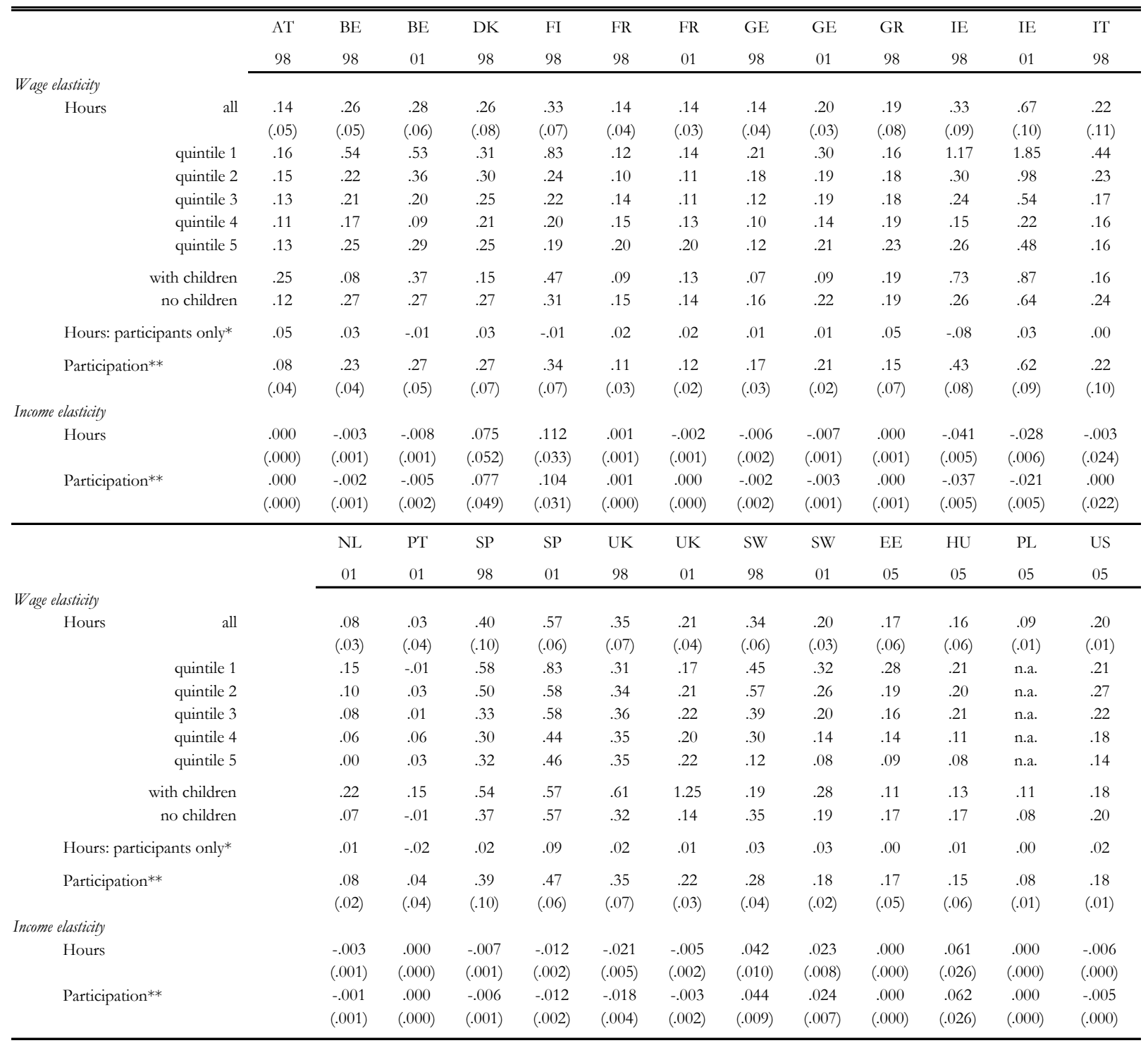

Note: elasticities are computed numerically by simulation of responses to a $1 \%$ uniform increase in wage rates or unearned income. Bootstrapped standard errors in brackets.

* pure intensive margin, ** pure extensive margin 


\section{Table 12: Robustness Checks}

\begin{tabular}{|c|c|c|c|c|c|c|c|c|c|c|c|c|c|c|}
\hline \multirow[b]{2}{*}{ Elasticity } & \multicolumn{2}{|c|}{ Alternative models } & \multirow{2}{*}{$\begin{array}{l}\text { AT } \\
98\end{array}$} & \multirow{2}{*}{$\begin{array}{l}\mathrm{BE} \\
98\end{array}$} & \multirow{2}{*}{$\begin{array}{l}\mathrm{BE} \\
01\end{array}$} & \multirow{2}{*}{$\begin{array}{l}\text { DK } \\
98\end{array}$} & \multirow{2}{*}{$\begin{array}{l}\text { FI } \\
98\end{array}$} & \multirow{2}{*}{$\begin{array}{l}\text { FR } \\
98\end{array}$} & \multirow{2}{*}{$\begin{array}{l}\text { FR } \\
01\end{array}$} & \multirow{2}{*}{$\begin{array}{l}\text { GE } \\
98\end{array}$} & \multirow{2}{*}{$\begin{array}{l}\text { GE } \\
01\end{array}$} & \multirow{2}{*}{$\begin{array}{l}\text { GR } \\
98\end{array}$} & \multirow{2}{*}{$\begin{array}{l}\text { IE } \\
98\end{array}$} & \multirow{2}{*}{$\begin{array}{l}\text { IE } \\
01\end{array}$} \\
\hline & $\begin{array}{l}\text { \# discrete } \\
\text { choices }\end{array}$ & $\begin{array}{l}\text { polynomial } \\
\text { order }\end{array}$ & & & & & & & & & & & & \\
\hline \multirow{8}{*}{$\begin{array}{l}\text { Total hours / } \\
\text { own-wage }\end{array}$} & 7 & 2 (baseline) & .34 & .28 & .31 & .30 & .13 & .23 & .13 & .31 & .31 & .62 & .47 & .32 \\
\hline & 7 & $2 *$ & .34 & .29 & .31 & .30 & .14 & .23 & .13 & .31 & .32 & .61 & .49 & .32 \\
\hline & 7 & $2 * *$ & .38 & .25 & .25 & .25 & .12 & .20 & .12 & .32 & .34 & .57 & .46 & .34 \\
\hline & 4 & 2 & .33 & .36 & .39 & .33 & .14 & .23 & .18 & .29 & .32 & .52 & .55 & .36 \\
\hline & 13 & 2 & .36 & .28 & .34 & .29 & .14 & .23 & .15 & .31 & .31 & .56 & .47 & .31 \\
\hline & 7 & 3 & .34 & .34 & .32 & .32 & .14 & .24 & .17 & .27 & .31 & .49 & .52 & .31 \\
\hline & 7 & 4 & .36 & .26 & .33 & .32 & .14 & .23 & .14 & .29 & .31 & .55 & .45 & .31 \\
\hline & 7 & $2 \$$ & .34 & .29 & .31 & .30 & .14 & .22 & .15 & .30 & .31 & .54 & .47 & .31 \\
\hline \multirow{8}{*}{$\begin{array}{c}\text { Participation / } \\
\text { own-wage }\end{array}$} & 7 & 2 (baseline) & .27 & .22 & .23 & .25 & .12 & .19 & .10 & .24 & .22 & .57 & .42 & .27 \\
\hline & 7 & $2 *$ & .28 & .23 & .23 & .25 & .13 & .19 & .11 & .23 & .22 & .57 & .43 & .27 \\
\hline & 7 & $2 * *$ & .33 & .21 & .20 & .19 & .11 & .16 & .10 & .25 & .25 & .54 & .37 & .26 \\
\hline & 4 & 2 & .29 & .28 & .30 & .27 & .13 & .21 & .15 & .25 & .28 & .49 & .51 & .31 \\
\hline & 13 & 2 & .29 & .22 & .25 & .24 & .13 & .19 & .11 & .23 & .20 & .53 & .41 & .26 \\
\hline & 7 & 3 & .28 & .27 & .24 & .27 & .13 & .20 & .13 & .23 & .23 & .49 & .48 & .28 \\
\hline & 7 & 4 & .28 & .21 & .25 & .27 & .13 & .21 & .12 & .24 & .22 & .55 & .44 & .29 \\
\hline & 7 & $2 \$$ & .27 & .22 & .23 & .25 & .12 & .18 & .12 & .23 & .21 & .51 & .41 & .26 \\
\hline \multirow{8}{*}{$\begin{array}{l}\text { Total hours / } \\
\text { income }\end{array}$} & 7 & 2 (baseline) & -.001 & -.002 & -.002 & -.004 & .001 & -.003 & -.002 & -.006 & -.006 & -.004 & -.008 & .007 \\
\hline & 7 & $2 *$ & -.001 & -.002 & -.002 & -.004 & .001 & -.003 & -.002 & -.006 & -.005 & -.004 & -.008 & .007 \\
\hline & 7 & $2 * *$ & .000 & -.001 & -.001 & .000 & .000 & -.007 & -.001 & -.004 & -.007 & .001 & -.008 & -.009 \\
\hline & 4 & 2 & -.001 & -.002 & -.001 & -.004 & .001 & -.002 & -.002 & -.006 & -.006 & -.005 & -.009 & .007 \\
\hline & 13 & 2 & -.001 & -.002 & -.002 & -.004 & .001 & -.003 & -.002 & -.006 & -.006 & -.005 & -.008 & .007 \\
\hline & 7 & 3 & -.001 & -.002 & -.002 & -.004 & .001 & -.003 & -.002 & -.006 & -.007 & -.006 & -.010 & .007 \\
\hline & 7 & 4 & -.001 & -.002 & -.002 & -.004 & .001 & -.003 & -.002 & -.006 & -.007 & -.006 & -.011 & .008 \\
\hline & 7 & $2 \$$ & -.001 & -.002 & -.001 & -.004 & .001 & -.003 & -.003 & -.005 & -.004 & -.004 & -.009 & .007 \\
\hline \multirow{8}{*}{$\begin{array}{l}\text { Participation / } \\
\text { income }\end{array}$} & 7 & 2 (baseline) & -.001 & -.002 & -.001 & -.003 & .001 & -.002 & -.002 & -.004 & -.004 & -.004 & -.007 & .007 \\
\hline & 7 & $2 *$ & -.001 & -.001 & -.001 & -.003 & .001 & -.002 & -.002 & -.004 & -.004 & -.003 & -.006 & .007 \\
\hline & 7 & $2 * *$ & .000 & .000 & .000 & .000 & .000 & -.006 & -.001 & -.001 & -.003 & .000 & -.005 & -.010 \\
\hline & 4 & 2 & -.001 & -.001 & -.001 & -.003 & .001 & -.002 & -.002 & -.005 & -.005 & -.004 & -.007 & .008 \\
\hline & 13 & 2 & -.001 & -.001 & -.001 & -.003 & .001 & -.002 & -.001 & -.004 & -.004 & -.004 & -.007 & .007 \\
\hline & 7 & 3 & -.001 & -.002 & -.001 & -.003 & .001 & -.002 & -.001 & -.003 & -.004 & -.004 & -.008 & .008 \\
\hline & 7 & 4 & -.001 & -.001 & -.001 & -.003 & .001 & -.001 & .000 & -.003 & -.004 & -.001 & -.009 & .008 \\
\hline & 7 & $2 \$$ & -.001 & -.001 & -.001 & -.003 & .001 & -.002 & -.002 & -.004 & -.003 & -.004 & -.007 & .007 \\
\hline
\end{tabular}

All values are estimated elasticities obtained by averaging predicted frequencies before and after uniform marginal increases of wage rates/unearned income, excepted:

* Average elasticities over 200 draws of the estimated parameters in their distribution

** Elasticities calculated using the calibration method (pseudo-residuals drawn to obtain a perfect match and retained after shock on wage/non-labor income)

Models' specifications vary with the number of choices in the discretization and the functional form of the utility fonction. We report here the order of the polynomial in consumption and hours (quadratic, cubic or quartic)

$\$$ is the baseline specification with a different addition to improve the flexibility of the model (fixed costs of work are replaced by part-time dummies). 
Table 13: Robustness Checks (cont.)

\begin{tabular}{|c|c|c|c|c|c|c|c|c|c|c|c|c|c|c|}
\hline \multirow{2}{*}{ Elasticity } & \multicolumn{2}{|c|}{ Alternative models } & \multirow{2}{*}{$\begin{array}{l}\text { IT } \\
98\end{array}$} & \multirow{2}{*}{$\begin{array}{l}\text { NL } \\
01\end{array}$} & \multirow{2}{*}{$\begin{array}{l}\text { PT } \\
01\end{array}$} & \multirow{2}{*}{$\begin{array}{l}\text { SP } \\
98\end{array}$} & \multirow{2}{*}{$\begin{array}{l}\text { SP } \\
01\end{array}$} & \multirow{2}{*}{$\begin{array}{l}\text { UK } \\
98\end{array}$} & \multirow{2}{*}{$\begin{array}{l}\text { UK } \\
01\end{array}$} & \multirow{2}{*}{$\begin{array}{l}\text { SW } \\
98\end{array}$} & \multirow{2}{*}{$\begin{array}{l}\text { SW } \\
01\end{array}$} & \multirow{2}{*}{$\begin{array}{l}\text { EE } \\
05\end{array}$} & \multirow{2}{*}{$\begin{array}{l}\mathrm{HU} \\
05\end{array}$} & \multirow{2}{*}{$\begin{array}{l}\text { US } \\
05\end{array}$} \\
\hline & $\begin{array}{l}\text { \# discrete } \\
\text { choices }\end{array}$ & $\begin{array}{l}\text { polynomial } \\
\text { order }\end{array}$ & & & & & & & & & & & & \\
\hline \multirow{8}{*}{$\begin{array}{c}\text { Total hours / } \\
\text { own-wage }\end{array}$} & 7 & 2 (baseline) & .33 & .32 & .14 & .63 & .51 & .12 & .09 & .16 & .11 & .08 & .15 & .14 \\
\hline & 7 & $2 *$ & .36 & .34 & .14 & .63 & .51 & .14 & .11 & .16 & .12 & .09 & .15 & .14 \\
\hline & 7 & $2 * *$ & .35 & .32 & .16 & .68 & .43 & .11 & .09 & .17 & .12 & .09 & .16 & .21 \\
\hline & 4 & 2 & .37 & .33 & .12 & .58 & .57 & .17 & .10 & .18 & .07 & .05 & .15 & .15 \\
\hline & 13 & 2 & .33 & .35 & .15 & .59 & .47 & .11 & .12 & .16 & .11 & .07 & .15 & .15 \\
\hline & 7 & 3 & .41 & .34 & .17 & .62 & .56 & .18 & .13 & .14 & .09 & .13 & .16 & .12 \\
\hline & 7 & 4 & .47 & .33 & .14 & .68 & .62 & .19 & .17 & .16 & .12 & .11 & .16 & .11 \\
\hline & 7 & $2 \$$ & .40 & .30 & .14 & .52 & .47 & .13 & .10 & .15 & .11 & .04 & .15 & .15 \\
\hline \multirow{8}{*}{$\begin{array}{c}\text { Participation / } \\
\text { own-wage }\end{array}$} & 7 & 2 (baseline) & .28 & .20 & .11 & .53 & .43 & .08 & .07 & .11 & .07 & .06 & .13 & .12 \\
\hline & 7 & $2 *$ & .32 & .22 & .11 & .54 & .43 & .10 & .09 & .12 & .07 & .07 & .13 & .12 \\
\hline & 7 & $2 * *$ & .27 & .18 & .11 & .55 & .34 & .07 & .08 & .12 & .07 & .08 & .15 & .18 \\
\hline & 4 & 2 & .32 & .25 & .11 & .53 & .51 & .14 & .09 & .16 & .05 & .05 & .13 & .14 \\
\hline & 13 & 2 & .28 & .22 & .12 & .50 & .40 & .08 & .09 & .11 & .06 & .05 & .13 & .12 \\
\hline & 7 & 3 & .42 & .22 & .15 & .57 & .50 & .12 & .10 & .09 & .05 & .10 & .13 & .09 \\
\hline & 7 & 4 & .47 & .22 & .12 & .61 & .54 & .13 & .12 & .10 & .06 & .09 & .13 & .08 \\
\hline & 7 & $2 \$$ & .35 & .19 & .11 & .44 & .40 & .09 & .07 & .10 & .06 & .04 & .13 & .12 \\
\hline \multirow{8}{*}{$\begin{array}{l}\text { Total hours / } \\
\text { income }\end{array}$} & 7 & 2 (baseline) & .001 & -.001 & .000 & -.001 & .000 & -.003 & -.002 & -.008 & -.002 & .000 & .000 & .000 \\
\hline & 7 & $2 *$ & -.002 & -.001 & .000 & -.001 & .000 & -.003 & -.002 & -.008 & -.002 & .000 & .000 & .000 \\
\hline & 7 & $2 * *$ & -.004 & -.003 & .000 & .000 & -.002 & -.003 & .002 & -.008 & -.001 & .000 & .000 & .080 \\
\hline & 4 & 2 & .001 & -.001 & .000 & .000 & .001 & -.003 & -.002 & -.008 & -.002 & .000 & .000 & .000 \\
\hline & 13 & 2 & -.001 & -.001 & .000 & .000 & .001 & -.003 & -.002 & -.008 & -.003 & .000 & .000 & .000 \\
\hline & 7 & 3 & -.001 & -.001 & .000 & -.002 & .002 & -.004 & -.003 & -.010 & -.003 & .000 & .000 & .001 \\
\hline & 7 & 4 & -.004 & -.001 & .000 & -.002 & .002 & -.002 & -.002 & -.008 & -.003 & .000 & .000 & .001 \\
\hline & 7 & $2 \$$ & -.003 & -.001 & .000 & .000 & .000 & -.002 & -.002 & -.008 & -.002 & .000 & .000 & .000 \\
\hline \multirow{8}{*}{$\begin{array}{c}\text { Participation / } \\
\text { income }\end{array}$} & 7 & 2 (baseline) & .001 & -.001 & .000 & .000 & .000 & -.002 & -.001 & -.004 & -.001 & .000 & .000 & .000 \\
\hline & 7 & $2 *$ & -.002 & -.001 & .000 & .000 & .000 & -.002 & -.001 & -.004 & -.001 & .000 & .000 & .000 \\
\hline & 7 & $2 * *$ & -.003 & -.002 & .000 & .000 & .002 & -.002 & .002 & -.003 & .000 & .000 & .000 & .079 \\
\hline & 4 & 2 & .001 & -.001 & .000 & .000 & .001 & -.002 & -.002 & -.006 & -.001 & .000 & .000 & .000 \\
\hline & 13 & 2 & -.001 & -.001 & .000 & .000 & .001 & -.002 & -.002 & -.003 & -.001 & .000 & .000 & .000 \\
\hline & 7 & 3 & .013 & -.001 & .000 & -.001 & .002 & -.003 & -.002 & -.006 & -.002 & .000 & .000 & .001 \\
\hline & 7 & 4 & .013 & .000 & .000 & -.002 & .002 & -.002 & -.002 & -.006 & -.002 & .000 & .000 & .001 \\
\hline & 7 & $2 \$$ & -.003 & -.001 & .000 & .000 & .000 & -.002 & -.001 & -.004 & -.001 & .000 & .000 & .000 \\
\hline
\end{tabular}

All values are estimated elasticities obtained by averaging predicted frequencies before and after uniform marginal increases of wage rates/unearned income, excepted:

* Average elasticities over 200 draws of the estimated parameters in their distribution

** Elasticities calculated using the calibration method (pseudo-residuals drawn to obtain a perfect match and retained after shock on wage/non-labor income)

Models' specifications vary with the number of choices in the discretization and the functional form of the utility fonction. We report here the order of the polynomial in consumption and hours (quadratic, cubic or quartic)

$\$$ is the baseline specification with a different addition to improve the flexibility of the model (fixed costs of work are replaced by part-time dummies). 